\title{
Review
}

\section{Structural and Insulating Behaviour of High-Permittivity Binary Oxide Thin Films for Silicon Carbide and Gallium Nitride Electronic Devices}

\author{
Raffaella Lo Nigro *, Patrick Fiorenza (D, Giuseppe Greco (D), Emanuela Schilirò and Fabrizio Roccaforte \\ Consiglio Nazionale delle Ricerche-Istituto per la Microelettronica e Microsistemi (CNR-IMM), \\ 95121 Catania, Italy; patrick.fiorenza@imm.cnr.it (P.F.); giuseppe.greco@imm.cnr.it (G.G.); \\ emanuela.schiliro@imm.cnr.it (E.S.); fabrizio.roccaforte@imm.cnr.it (F.R.) \\ * Correspondence: raffaella.lonigro@imm.cnr.it; Tel.: +39-095-596-8218
}

\begin{abstract}
High- $\kappa$ dielectrics are insulating materials with higher permittivity than silicon dioxide. These materials have already found application in microelectronics, mainly as gate insulators or passivating layers for silicon (Si) technology. However, since the last decade, the post-Si era began with the pervasive introduction of wide band gap (WBG) semiconductors, such as silicon carbide (SiC) and gallium nitride $(\mathrm{GaN})$, which opened new perspectives for high- $\mathrm{k}$ materials in these emerging technologies. In this context, aluminium and hafnium oxides (i.e., $\mathrm{Al}_{2} \mathrm{O}_{3}, \mathrm{HfO}_{2}$ ) and some rare earth oxides (e.g., $\mathrm{CeO}_{2}, \mathrm{Gd}_{2} \mathrm{O}_{3}, \mathrm{Sc}_{2} \mathrm{O}_{3}$ ) are promising high- $\mathrm{k}$ binary oxides that can find application as gate dielectric layers in the next generation of high-power and high-frequency transistors based on $\mathrm{SiC}$ and GaN. This review paper gives a general overview of high-permittivity binary oxides thin films for post-Si electronic devices. In particular, focus is placed on high- $\mathrm{k}$ binary oxides grown by atomic layer deposition on WBG semiconductors (silicon carbide and gallium nitride), as either amorphous or crystalline films. The impacts of deposition modes and pre- or postdeposition treatments are both discussed. Moreover, the dielectric behaviour of these films is also presented, and some examples of high- $\kappa$ binary oxides applied to $\mathrm{SiC}$ and $\mathrm{GaN}$ transistors are reported. The potential advantages and the current limitations of these technologies are highlighted.
\end{abstract}

Keywords: insulators; binary oxides; high-k dielectrics; power electronics; wide band gap semiconductors

Electronic Devices.

Materials 2022, 15, 830. https://

doi.org/10.3390/ ma15030830

Academic Editor: Alexander

N. Obraztsov

Received: 17 December 2021

Accepted: 19 January 2022

Published: 22 January 2022

Publisher's Note: MDPI stays neutral with regard to jurisdictional claims in published maps and institutional affiliations.

Copyright: (c) 2022 by the authors. Licensee MDPI, Basel, Switzerland. This article is an open access article distributed under the terms and conditions of the Creative Commons Attribution (CC BY) license (https:// creativecommons.org/licenses/by/ $4.0 /)$.

\section{Introduction}

Today, it is widely recognized that microelectronic devices have improved the quality of our daily lives, strongly contributing to the development of human civilization. In the 1940s-1950s, the first microelectronic devices appeared, and they were based on germanium. However, silicon ( $\mathrm{Si}$ ) gradually began to be the semiconductor of choice, driving the power electronics revolution with the introduction of the first $\mathrm{p}-\mathrm{n}-\mathrm{p}-\mathrm{n}$ transistors in 1956 at Bell Laboratories [1,2]. About two decades later, the introduction of metal-oxide-semiconductor field-effect transistors (Si-MOSFETs) set the foundations for the development of the modern CMOS technology [3]. Hence, for about fifty years, microelectronics have been based mainly on Si semiconductors. The great success of digital technology may apparently indicate that $\mathrm{Si}$ is still the most suitable material for microelectronic devices. However, in other fields, such as electronic systems for power transmission or distribution (power converters, base stations, wireless connections, etc.) and optoelectronics (light emitting diodes-LEDs, lasers), the achievement of the ultimate silicon performances opened the route for the post-Si era. In this context, wide band gap (WBG) semiconductors emerged as the most suitable materials for this technological revolution, especially in high-power and high-frequency electronics [4-7].

Among the WBG semiconductors, silicon carbide ( $\mathrm{SiC})$ and gallium nitride $(\mathrm{GaN})$ are the most attractive candidates because they already provide a good compromise between 
their theoretical properties (blocking voltage capability, operation temperature, and switching frequency) and commercial availability [4-6]. Their wide band gaps result in higher breakdown voltage and operation temperature with respect to $\mathrm{Si}$, so both are excellent candidates to replace Si in the next generation of high-power and high-frequency electronics. Because of their different physical and electronic properties in terms of carrier mobility and thermal conductivity [8,9], $\mathrm{SiC}$ and $\mathrm{GaN}$ will cover different market segments in the post-Si technologies [10]. In particular, $\mathrm{SiC}$ is more suitable for high-power applications based on vertical devices, while $\mathrm{GaN}$ is more efficient for high-frequency applications based on lateral transistors. In any case, both materials can provide superior performances with respect to the existing Si devices [5,6], although the different technological steps for transistor fabrication need to be appropriately integrated.

Gate insulators are certainly the most important brick for transistor operation, even in the post-Si era, since the device performances critically depend on the choice of the insulating material. However, gate insulator technology is rather different in $\mathrm{SiC}$ and $\mathrm{GaN}$, thus leading to a variety of issues to be faced when developing devices on these two WBG semiconductors.

Traditional dielectric materials, such as silicon oxide or silicon nitride, have also been widely investigated [11-14] for applications based on WBG semiconductors. However, the performance of the ideal $\mathrm{Si} / \mathrm{SiO}_{2}$ system has been not achieved, and attention has been focused on the so-called "high- $\kappa$ " oxides [15-20]. Among all the high- $\kappa$ materials, some binary oxides (such as $\mathrm{Al}_{2} \mathrm{O}_{3}$ [21,22], $\mathrm{HfO}_{2}$ [22], $\mathrm{NiO}[23,24], \mathrm{CeO}_{2}$ [25], $\mathrm{Sc}_{2} \mathrm{O}_{3}$ [26,27], $\mathrm{La}_{2} \mathrm{O}_{3}$ [28], $\mathrm{Gd}_{2} \mathrm{O}_{3}$ [28], $\mathrm{Y}_{2} \mathrm{O}_{3}[28,29], \mathrm{ZrO}_{2}$, [17,18], $\mathrm{Ga}_{2} \mathrm{O}_{3}$ [30], etc.) potentially represent a suitable solution for the integration in WBG-based devices because of their higher chemical stability and/or lower fabrication cost. Some other possible materials have been studied, such as ternary oxides and nitrides, but those materials are beyond the topic of this review paper.

Table 1 shows a summary of the possible oxide candidates for the replacement of the $\mathrm{SiO}_{2}$ dielectric material and their principal physical properties, such as dielectric constant values, band gaps, and crystallization temperatures.

Table 1. Principal physical properties of high-k gate binary oxides.

\begin{tabular}{ccccc}
\hline Oxide & Dielectric Constant & Band Gap (eV) & Crystallization Temperature & Ref \\
\hline $\mathrm{Al}_{2} \mathrm{O}_{3}$ & 10 & 9 & $900{ }^{\circ} \mathrm{C}$ & {$[17,18]$} \\
\hline $\mathrm{HfO}_{2}$ & $\sim 20$ & $5.6-5.8$ & $500{ }^{\circ} \mathrm{C}$ & {$[17,18,22]$} \\
\hline $\mathrm{NiO}$ & 11.7 & 4 & $300{ }^{\circ} \mathrm{C}$ & {$[23,24]$} \\
\hline $\mathrm{CeO}_{2}$ & 26 & 6 & $500^{\circ} \mathrm{C}$ & {$[25]$} \\
\hline $\mathrm{Sc}_{2} \mathrm{O}_{3}$ & $12-14$ & 6.0 & $>400{ }^{\circ} \mathrm{C}$ & {$[26-29]$} \\
\hline $\mathrm{Y}_{2} \mathrm{O}_{3}$ & 10 & 5.5 & $>400{ }^{\circ} \mathrm{C}$ & {$[26,28,29]$} \\
\hline $\mathrm{Gd}_{2} \mathrm{O}_{3}$ & $\sim 20$ & $5.0-5.45$ & $>400{ }^{\circ} \mathrm{C}$ & {$[26,28]$} \\
\hline $\mathrm{La}_{2} \mathrm{O}_{3}$ & $\sim 20$ & $5.4-5.6$ & $>400{ }^{\circ} \mathrm{C}$ & {$[17,18,27,29]$} \\
\hline $\mathrm{ZrO}_{2}$ & 25 & 5.8 & $>400{ }^{\circ} \mathrm{C}$ & {$[17,18]$} \\
\hline $\mathrm{Ga}_{2} \mathrm{O}_{3}$ & $\sim 10$ & 5 & $>500{ }^{\circ} \mathrm{C}$ & {$[30]$} \\
\hline
\end{tabular}

Figure 1a reports the values of the band gaps of different insulators as a function of their relative permittivity (in units of the vacuum permittivity $\varepsilon_{0}$ ). The general trend (highlighted by the continuous line) is a decrease in the band gap with increasing permittivity. Hence, the reduced band gap of high-permittivity oxides can represent a concern in terms of leakage current. For this reason, insulators with appropriate band alignment with the semiconductor must be preferred. In this context, Figure $1 \mathrm{~b}$ shows the band alignment of several high-k oxides with the semiconductor materials under consideration (i.e., $\mathrm{Si}$, $4 \mathrm{H}-\mathrm{SiC}$, and $\mathrm{GaN}$ ). The offset between the conduction bands of the semiconductors and insulators is reported in scale. 


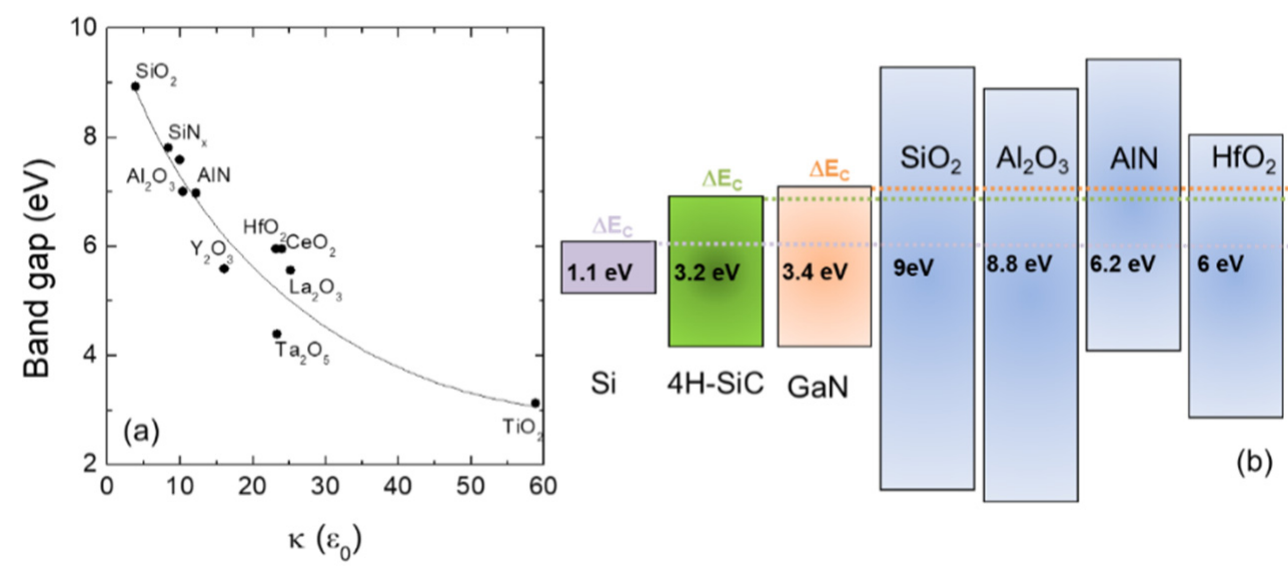

Figure 1. (a) Band gap values as a function of relative permittivity (in units of the vacuum permittivity $\varepsilon_{0}$ ) for different insulators. The continuous line is a guide; (b) schematic illustration (in scale) of the band alignments of some common insulators with the semiconductor materials under consideration (i.e., silicon, $4 \mathrm{H}-\mathrm{SiC}$, and $\mathrm{GaN}$ ). The light purple, green, and orange dotted lines indicate the conduction band edge of the $\mathrm{Si}, 4 \mathrm{H}-\mathrm{SiC}$, and $\mathrm{GaN}$ semiconductors, respectively.

Hence, in terms of physical properties, the guidelines for the choice of the ideal gate dielectric material are: (i) high dielectric constant value; (ii) appropriate alignment of the band gap with respect to the substrates (in particular, the band offset should be greater than $1 \mathrm{eV}$ ); (iii) thermal stability during the fabrication process (many steps have to be carried out at high temperatures for short periods of time) [17-19].

Moreover, since the gate oxide is directly in contact with the device channel, another important requirement is good quality of the gate oxide/semiconductor interface in terms of low roughness and low density of electronic defects [5].

These requirements could be met throughout two possible approaches, i.e., a crystalline gate oxide epitaxially grown on the semiconducting substrate or an amorphous oxide. Electronic defects can be thus minimized either by exactly or randomly saturating the dangling bonds, respectively. Generally, amorphous oxides are the preferred solution, since they possess isotropic dielectric constants due to the fluctuation of the polarized bonds and do not possess rough edges. By contrast, the advantage of the epitaxial oxides is the abruptness of the interface $[17,18]$.

In general, as schematically illustrated in Figure 2, structural and compositional defects of binary oxides (e.g., oxygen vacancies, impurities, etc.) can generate the presence of energetic levels within the band gap or at the interface, and the trapped charges in these states are undesirable for the following reasons: (i) they are responsible for a shift in the voltage threshold of the transistor; (ii) they may change over time and determine the instability of the transistor output characteristics; (iii) they scatter the carriers in the inversion channel and, consequently, limit the channel mobility; (iv) they compromise the transistor reliability because they are the main cause of the dielectric breakdown [17,18].

Silicon dioxide $\left(\mathrm{SiO}_{2}\right)$ [15] was considered an ideal dielectric during the $\mathrm{Si}$ era because it possesses a very low electronic defect density. The reason for this is the low coordination number, which guarantees the possibility to "repair" the dangling bonds. On the other hand, alternative high- $\mathrm{k}$ oxides possess chemical bonds that cannot easily relax, thus inevitability leading to a higher electronic defect density. Hence, there is a need to reduce the number of electronic defects in these materials by annealing treatments or by optimizing their deposition processes. 


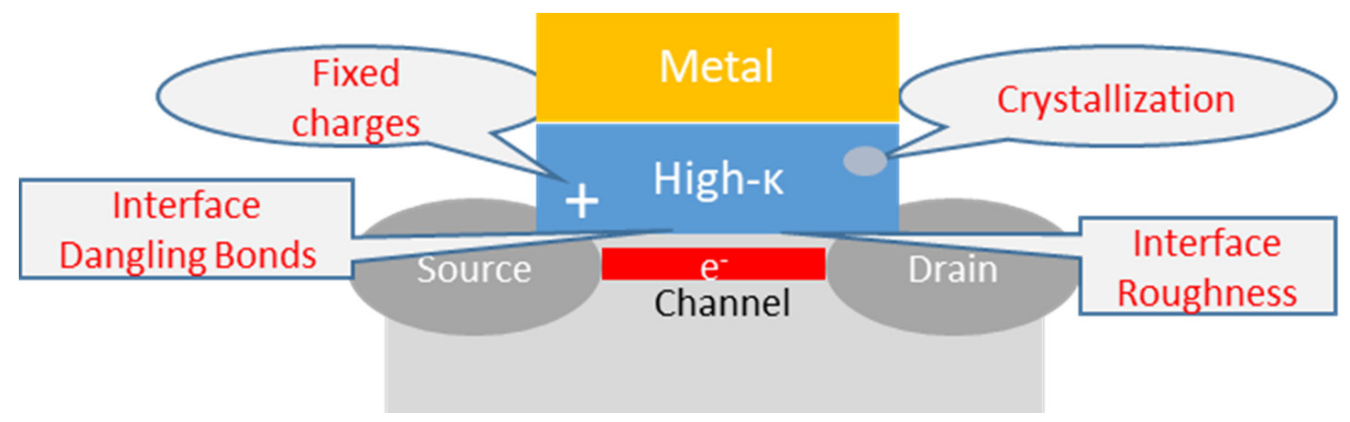

Figure 2. Schematic representation of the main issues affecting the functionality of high- $\mathrm{k}$ binary gate oxides in a transistor.

In this context, the important role of the growth technique for the deposition of the high- $\kappa$ dielectric layers is clear. Certainly, many deposition techniques based on either physical or chemical principles are available. However, the semiconductor industry currently demands manufacturing techniques able to achieve good surface coverage on large areas, high conformity on three-dimensional structures, high growth rate, reliability, and compatibility with the thermal budget required for the device fabrication [31,32].

Table 2 compares the main features of the common growth techniques used [29] for the deposition of high-k oxide thin films for microelectronics applications, considering the different deposition parameters. High deposition rates and large varieties of available materials are certainly the main advantages of molecular beam epitaxy (MBE) or chemical vapor deposition (CVD) methods. By contrast, these techniques are characterized by the need for high deposition temperatures. Physical vapor deposition (PVD)-based techniques are generally preferred for metals rather than for insulator deposition and lack uniformity over large areas.

Table 2. Comparison of the main features of the common deposition techniques for high-k oxides in microelectronics [29,31,32].

\begin{tabular}{|c|c|c|c|c|}
\hline & ALD & MBE & CVD & PVD \\
\hline Thickness range & $\leq 2000 \AA$ & $\leq 2000 \AA$ & $\geq 100 \AA$ & $\geq 100 \AA$ \\
\hline Deposition rate & $\begin{array}{c}\text { Low } \\
1-5 \mathrm{~nm} / \mathrm{min}\end{array}$ & $\begin{array}{c}\text { High } \\
0.01-0.3 \mu \mathrm{m} / \mathrm{min}\end{array}$ & $\begin{array}{l}\text { High } \\
1-10 \mu \mathrm{m} / \mathrm{h}\end{array}$ & $\begin{array}{c}\text { Medium } \\
0.1-1 \mu \mathrm{m} / \mathrm{h}\end{array}$ \\
\hline $\begin{array}{l}\text { Step coverage } \\
\text { Aspect ratio }\end{array}$ & $\begin{array}{c}100 \% \\
60: 1\end{array}$ & $\begin{array}{c}25-50 \% \\
1: 1\end{array}$ & $\begin{array}{l}70 \% \\
1: 1\end{array}$ & $\begin{array}{c}25-50 \% \\
1: 1\end{array}$ \\
\hline Deposition temperature & $25-400^{\circ} \mathrm{C}$ & $500-1000{ }^{\circ} \mathrm{C}$ & $300-1100{ }^{\circ} \mathrm{C}$ & $200-500^{\circ} \mathrm{C}$ \\
\hline Film type availability & $\begin{array}{c}\text { High } \\
\text { (limited for metals) }\end{array}$ & $\begin{array}{c}\text { High } \\
\text { (limited for Metals) }\end{array}$ & $\begin{array}{c}\text { High } \\
\text { (limited for metals) }\end{array}$ & $\begin{array}{l}\text { High for metals and } \\
\text { conductive materials }\end{array}$ \\
\hline
\end{tabular}

However, judging from the latest industrial trends and looking forward at the nanometric-scale miniaturization process of electronic devices, the employment of deposition methods with atomic-level accuracy has become mandatory. From this perspective, atomic layer deposition (ALD) is the most promising deposition technique, and it is gradually replacing CVD and PVD techniques in many applications.

ALD is an innovative thin-film growth method that belongs to the general class of CVD techniques. As in a typical CVD process, films are deposited from gaseous chemical precursors, one for each element of the desired compound. However, unlike the traditional CVD mechanism, the ALD process is characterized by "self-limited" reactions, first between precursor and pristine surface and second on a surface saturated by one "monolayer" of precursor fragments [31]. This deposition mechanism allows subnanometer control of film thickness, conformal coating of nonplanar substrates (step coverage $100 \%$ ), and high-quality films deposited at relatively low temperatures [32]. For these reasons, the 
employment of ALD can give several advantages over that of either CVD or PVD. Finally, the low growth rate of the classical thermal ALD (T-ALD) process has been now significantly improved by the implementation of plasma enhanced ALD (PE-ALD). PE-ALD is an energyenhanced deposition technique based on plasma ignition to enhance the co-reactants' reactivity. The high reactivity of the plasma species produces a higher density of reactive surface sites. Consequently, higher growth rates and better properties of the resulting films in terms of density, impurity content, and electrical parameters can be obtained. Another advantage of PE-ALD is the possibility to control additional process parameters, such as the operating pressure, plasma power, and plasma exposure time. Varying the plasma parameters enable fine tuning the properties of the deposited films.

A great part of the results presented in the following Sections are related to high- $\mathrm{k}$ oxides grown by ALD techniques.

\section{Amorphous High-k Oxides on WBG Semiconductors}

Several amorphous materials have been studied in the last decades as possible high- $\mathrm{K}$ gate oxides for WBG semiconductors. Among them, because of their high crystallization temperature, $\mathrm{Al}_{2} \mathrm{O}_{3}$ thin films have certainly been the most widely investigated solution as amorphous dielectric layers. Some studies have reported on $\mathrm{Al}_{2} \mathrm{O}_{3}$ formed by reactive ion sputtering [33-35], oxidation of $\mathrm{Al}$ in oxygen ambient at high temperatures [36], and a few others nonconventional techniques $[37,38]$. The major drawbacks of these solutions are the low breakdown fields (around 5-6 $\mathrm{MVcm}^{-1}$ ) of the deposited films and their poor thickness uniformity on large areas. These limitations have been overcome by the implementation of the ALD technique, which has been the method of choice to study the potentiality of $\mathrm{Al}_{2} \mathrm{O}_{3}$ thin films [39-44].

However, several issues still remain objects of investigation in order to optimize the quality of deposited materials and their interfaces with the WBG semiconductors. Moreover, though the growth of high-K oxides amorphous films is generally carried out at low deposition temperatures (in the $200-300{ }^{\circ} \mathrm{C}$ range), some interfacial interaction could occur in $\mathrm{SiC}$ and $\mathrm{GaN}$ substrates, resulting in the presence of unwanted materials or deposition by products.

In this context, the cleaning of the substrate surface before dielectric deposition, as well as the postdeposition annealing treatments, are discussed in the next subsections, illustrating as examples some relevant case studies of amorphous high- $\mathrm{k}$ oxides on $\mathrm{SiC}$ and GaN substrates.

\subsection{Growth of Amorphous High-k Oxides on SiC}

Unlike that of thermal silicon dioxide $\left(\mathrm{SiO}_{2}\right)$, the growth of high-k oxides on silicon carbide is much more affected by the quality of the semiconductor surface. In fact, in order to limit the amount of the interface state density $\left(\mathrm{D}_{\mathrm{it}}\right)$, appropriate cleaning of the $\mathrm{SiC}$ surfaces is always required.

A variety of $\mathrm{SiC}$ surface-cleaning treatments have been proposed, based either on wet chemical solutions [44-46] or plasma [47-49]. The most used chemical solutions for SiC cleaning are combinations of diluted sulfuric acid, hydrogen peroxide, isopropanol, diluted hydrofluoric acid. Suvanam et al. [46] demonstrated that RCA treatment [45], followed by HF diluted solution and finally isopropanol, was a good route to improve the interfacial electrical characteristics of $\mathrm{Al}_{2} \mathrm{O}_{3}$ films on $\mathrm{SiC}$, obtaining a density of interface states $\mathrm{D}_{\mathrm{it}}=1.5 \times 10^{11} \mathrm{eV}^{-1} \mathrm{~cm}^{-2}$ at $\mathrm{E}_{\mathrm{C}}-\mathrm{E}_{\mathrm{t}}=0.2 \mathrm{eV}$ below the $4 \mathrm{H}-\mathrm{SiC}$ conduction band edge, which was about two orders of magnitude lower than the values found with thermal $\mathrm{SiO}_{2}$. In regard to plasma treatment before high- $\mathrm{K}$ deposition, $\mathrm{H}_{2}$ plasma has been also evaluated in some works [47-49], since it represents an efficient route for the passivation of dangling bonds on $\mathrm{SiC}$ surfaces. Heo et al. [49] measured promising values of interface state density $\left(D_{i t}=6 \times 10^{12} \mathrm{eV}^{-1} \mathrm{~cm}^{-2}\right.$ at $\left.\mathrm{E}_{\mathrm{C}}-\mathrm{E}_{\mathrm{t}}=0.2 \mathrm{eV}\right)$ when a $15 \mathrm{~min}$ long $\mathrm{H}_{2}$ plasma treatment was performed before deposition and after the post-metallization step. 
As a matter of fact, besides surface treatments before the dielectric deposition, postdeposition annealings are of great importance to optimize the dielectric properties. Many parameters can in principle be varied, such as ambient atmosphere, annealing temperature and time, etc. However, these processing steps must be ultimately compatible with complete $\mathrm{SiC}$ device fabrication, in which, e.g., the formation of metal contacts is achieved at high temperatures $\left(900-1000{ }^{\circ} \mathrm{C}\right)$ and fixed gas atmospheres $\left(\mathrm{N}_{2}\right.$ or Ar). Generally, a large number of high- $\mathrm{K}$ oxides possess crystallization temperatures of about $400-500{ }^{\circ} \mathrm{C}$, with $\mathrm{Al}_{2} \mathrm{O}_{3}$ being the most thermally stable at up to $800^{\circ} \mathrm{C}$. However, independently of the chemical nature of the high- $\mathrm{K}$ oxide, the annealing process can improve dielectrical properties. For instance, Wang et al. [50] demonstrated the beneficial effects of high-temperature annealings $\left(800-1000{ }^{\circ} \mathrm{C}\right)$ performed in $\mathrm{O}_{2}$ atmosphere on $\mathrm{Al}_{2} \mathrm{O}_{3}$ films. In particular, they showed that although $\mathrm{Al}_{2} \mathrm{O}_{3}$ films started crystallizing at $900{ }^{\circ} \mathrm{C}$, capacitance vs. voltage $(\mathrm{C}-\mathrm{V})$ measurements revealed their improved electrical characteristics (i.e., reduced hysteresis phenomena). Hence, the authors concluded that annealing at $900{ }^{\circ} \mathrm{C}$ represented the best option in terms of both surface morphology and dielectric quality. On the other hand, many other papers demonstrated that such high annealing temperatures induce the formation of a thin stoichiometric or sub-stoichiometric silicon oxide interfacial layer [33,50-52]. This oxidation phenomenon can have a detrimental impact on the properties of high- $\mathrm{K} / \mathrm{SiC}$ interfaces, including in the case of abrupt $\mathrm{Al}_{2} \mathrm{O}_{3} / 4 \mathrm{H}-\mathrm{SiC}$ interfaces obtained by ALD growth [40,53-55]. In this context, annealing in $\mathrm{N}_{2}$ atmosphere can be the preferred solution, although uncontrolled $\mathrm{SiO}_{x}$ formation can occur in $\mathrm{N}_{2}$ atmosphere for high annealing temperatures. Moreover, Avice et al. [42] and Khosa et al. [36] showed that an additional effect of incomplete $\mathrm{SiC}$ oxidation was the formation of $\mathrm{C}$ clusters if not enough oxygen was present to enable the out-diffusion of carbon as carbon monoxide. The formation of the SiOx interfacial layers was observed independently of the annealing temperature or ambient. In fact, this phenomenon has been observed even in vacuum or at only $300{ }^{\circ} \mathrm{C}$ annealing temperature [55]. Hence, it is expected that the elimination of residual $\mathrm{O}_{2}$ molecules in the annealing ambient is one the key issues for the limitation of $\mathrm{SiOx}$ formation.

In general, most of the reported postdeposition annealing studies were carried out in oxidizing $\left(\mathrm{O}_{2}\right.$ or $\left.\mathrm{N}_{2} \mathrm{O}\right)$ or non-oxidizing $\left(\mathrm{Ar}, \mathrm{N}_{2}\right.$ or forming gas) ambient, in the $500-1100{ }^{\circ} \mathrm{C}$ temperature range, and for short $(1 \mathrm{~min})$ or long $(1-2 \mathrm{~h})$ times. An interaction at the interface has always been observed by the formation of the silicon oxide layers and carbon clusters. The control of the chemical nature of the interface products, which in turn strongly affects the electrical characteristics, is not trivial.

In this context, Schilirò et al. $[39,40]$ reported an interesting comparison between the properties of $\mathrm{Al}_{2} \mathrm{O}_{3}$ thin films grown by PE-ALD on bare $4 \mathrm{H}-\mathrm{SiC}$ and on a $5 \mathrm{~nm}$ thermal $\mathrm{SiO}_{2} / \mathrm{SiC}$ stack. TEM analyses (shown in Figure $3 \mathrm{a}, \mathrm{b}$ ) showed uniform interfaces and well adherent films. The surface morphology of the films (determined by AFM) was very similar, with root-mean-square (RMS) values measured over a $1 \mu \mathrm{m}^{2}$ area of $0.670 \mathrm{~nm}$ and $0.561 \mathrm{~nm}$ for $\mathrm{Al}_{2} \mathrm{O}_{3} / \mathrm{SiC}$ and $\mathrm{Al}_{2} \mathrm{O}_{3} / \mathrm{SiO}_{2} / \mathrm{SiC}$ samples, respectively.

Though the interface structural quality appears analogous, quite different electrical properties were measured on MOS capacitors. In fact, current vs. voltage (I-V) measurements (Figure 3d) showed a higher leakage current in the $\mathrm{Al}_{2} \mathrm{O}_{3} / \mathrm{SiC}$ than in the $\mathrm{Al}_{2} \mathrm{O}_{3} / \mathrm{SiO}_{2} / \mathrm{SiC}$ stack. Furthermore, the breakdown fields, i.e., $5.7 \mathrm{MV} / \mathrm{cm}$ for the $\mathrm{Al}_{2} \mathrm{O}_{3} / \mathrm{SiC}$ and $7 \mathrm{MV} / \mathrm{cm}$ for the $\mathrm{Al}_{2} \mathrm{O}_{3} / \mathrm{SiO}_{2} / \mathrm{SiC}$, demonstrated the better electrical quality obtained by the introduction of the $\mathrm{SiO}_{2}$ at the interface. Moreover, the relative permittivity values, evaluated from the $\mathrm{C}-\mathrm{V}$ curves (Figure $3 \mathrm{c}$ ), were $\varepsilon \approx 6.7$ and $\varepsilon \approx 8.4$ for the $\mathrm{Al}_{2} \mathrm{O}_{3} / \mathrm{SiC}$ and the $\mathrm{Al}_{2} \mathrm{O}_{3} / \mathrm{SiO}_{2} / \mathrm{SiC}$ samples, respectively.

These results can be explained by considering both the larger conduction band offset between the $\mathrm{SiO}_{2}$ and the $\mathrm{SiC}$ substrate (Figure $1 \mathrm{~b}$ ) and the different chemical impact of the substrate surface on the $\mathrm{Al}_{2} \mathrm{O}_{3}$ nucleation process. This latter is schematically depicted in Figure 4, showing that the presence of the $\mathrm{OH}$ species on the $\mathrm{SiO}_{2}$ surface favours the 
nucleation process by increasing the number of nucleation sites and the formation of denser $\mathrm{Al}_{2} \mathrm{O}_{3}$ films.
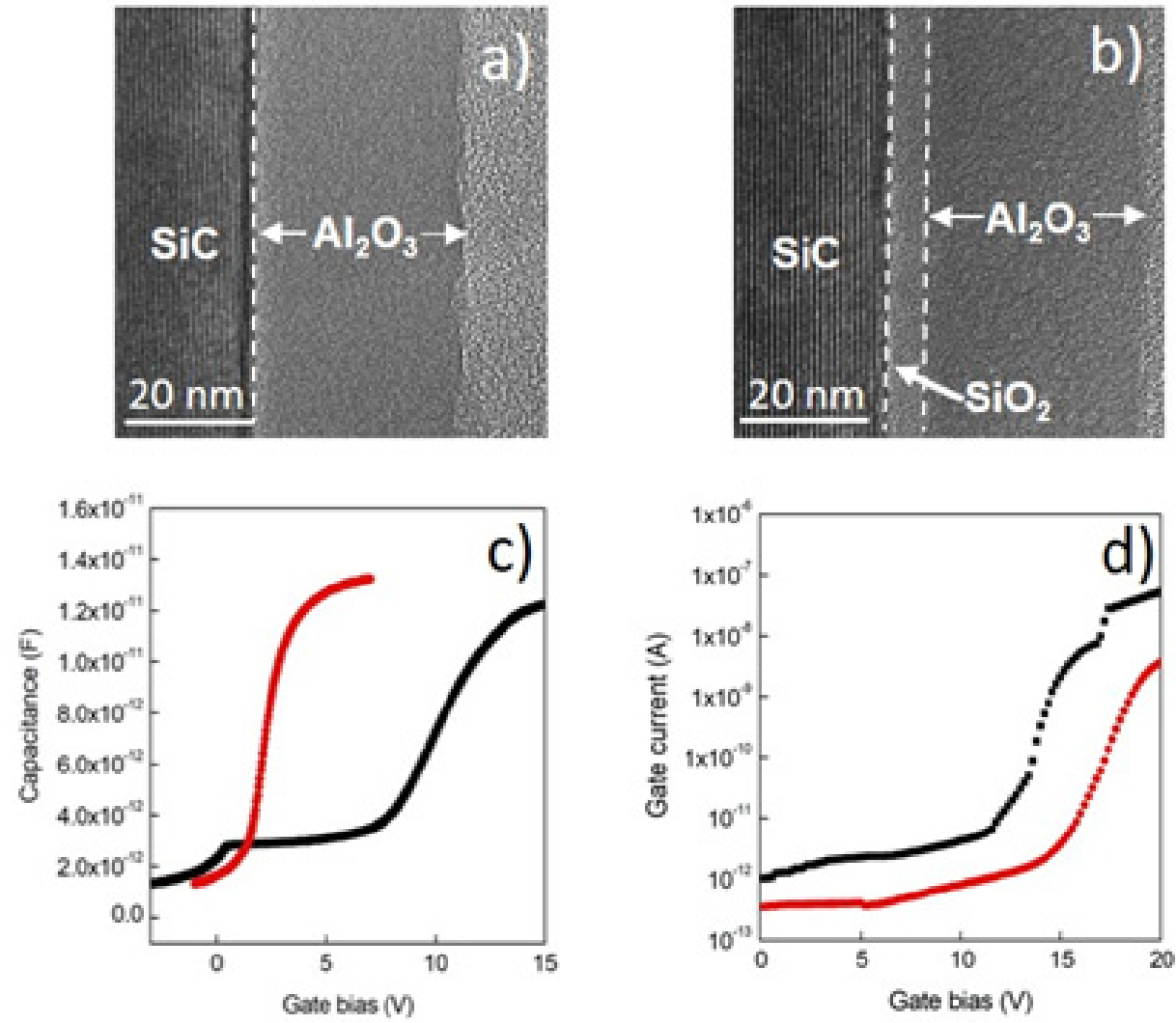

Figure 3. TEM images of $\mathrm{Al}_{2} \mathrm{O}_{3}$ thin films grown by PE-ALD on $4 \mathrm{H}-\mathrm{SiC}(\mathbf{a})$ and $\mathrm{SiO}_{2} / 4 \mathrm{H}-\mathrm{SiC}(\mathbf{b})$ substrates and their relative electrical characteristics in terms of $\mathrm{C}-\mathrm{V}$ curves (c) and I-V measurements (d) performed on MOS capacitors. Black and red lines are related to $\mathrm{Al}_{2} \mathrm{O}_{3}$ thin films deposited on $\mathrm{SiO}_{2} / 4 \mathrm{H}-\mathrm{SiC}$ and $4 \mathrm{H}-\mathrm{SiC}$ substrates, respectively. Reproduced with permission from [40]. Copyright (C) 2016 WILEY-VCH Verlag GmbH \& Co. KGaA.

a)

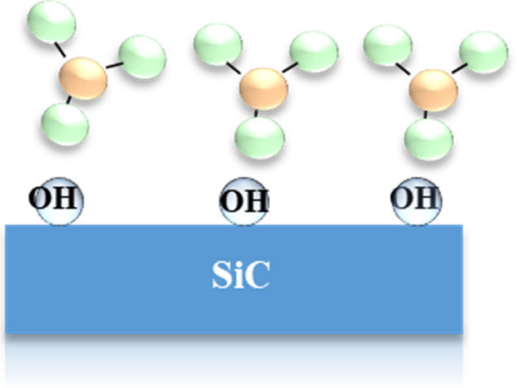

b)

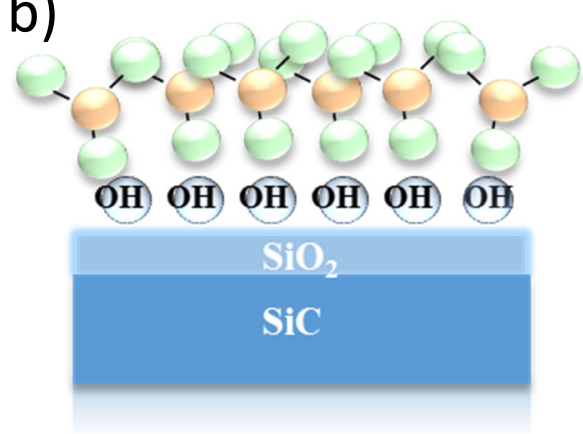

Figure 4. Schematic representation of the chemical impact of the different substrate surfaces on the $\mathrm{Al}_{2} \mathrm{O}_{3}$ nucleation processes, in the case of a bare $\mathrm{SiC}$ substrate (a) or a $\mathrm{SiC}$ substrate with a thin $\mathrm{SiO}_{2}$ layer on the top (b). Reproduced with permission from [40]. Copyright (C) 2016 WILEY-VCH Verlag $\mathrm{GmbH} \& \mathrm{Co}$. KGaA.

Other high-k oxides have been also grown on $\mathrm{SiC}$ substrates as thin amorphous films, such as $\mathrm{HfO}_{2}$ [56-58], $\mathrm{La}_{2} \mathrm{O}_{3}[59,60], \mathrm{Ta}_{2} \mathrm{O}_{5}$ [61], and $\mathrm{TiO}_{2}$ [62]. Among these materials, $\mathrm{HfO}_{2}$ thin films have been widely investigated because of their superior theoretical 
properties, such as much higher permittivity. However, the main drawback for their implementation on SiC-based devices is the imperfect alignment of both conduction and valence band offsets (about 0.7 and $1.74 \mathrm{eV}$, respectively) with those of SiC. Cheong et al. [56,57] reported on $\mathrm{HfO}_{2}$ films with a very high dielectric constant value (20), but the interface state density $D_{\text {it }}$ was as high as $2 \times 10^{13} \mathrm{eV}^{-1} \mathrm{~cm}^{-2}$, which give no advantage with respect to the $\mathrm{SiO}_{2} / \mathrm{SiC}$ system. Moreover, very high leakage current densities of $1 \mathrm{~mA} \mathrm{~cm}{ }^{-2}$ were already recorded in an electric field as low as $0.3 \mathrm{MVcm}^{-1}$ by Afanas'ev et al. [58]. While in this case, the high leakage current could in principle be mitigated by the introduction of a $\mathrm{SiO}_{2}$ layer at the $\mathrm{SiC}$ interfaces, a further issue to be considered is the low thermal stability of $\mathrm{HfO}_{2}$ at temperatures higher than $500{ }^{\circ} \mathrm{C}$, when crystallization starts to occur.

In order to maintain the best features of $\mathrm{HfO}_{2}$ (i.e., high permittivity) and $\mathrm{Al}_{2} \mathrm{O}_{3}$ (i.e., high crystallization temperature), these two materials have been evaluated in combined laminated systems.

In this context, some $\mathrm{Al}_{2} \mathrm{O}_{3} / \mathrm{HfO}_{2}$ bilayer systems deposited on thermally oxidized $4 \mathrm{H}-\mathrm{SiC}$ substrate have been studied, the most complex stack being an $\mathrm{Al}_{2} \mathrm{O}_{3} / \mathrm{HfO}_{2}$ multilayer laminated system [63]. The $\mathrm{Al}_{2} \mathrm{O}_{3} / \mathrm{HfO}_{2}$ nanolaminate shown (Figure 5a) had a total thickness of $38 \mathrm{~nm}$ and perfectly distinguishable sublayers, each with thickness of about $1.4-1.8 \mathrm{~nm}$. After annealing treatment at $800{ }^{\circ} \mathrm{C}$ in $\mathrm{N}_{2}$ atmosphere, the interfaces between the sublayers (Figure $5 b$ ) became less sharp, and an intermixing process occurred. Notably, both the as-deposited and annealed samples showed amorphous structures. AFM investigation pointed to a smooth surface morphology with a low RMS value of $0.6 \mathrm{~nm}$, which was maintained in the annealed sample. A dielectric constant value of 12.4 was determined by the accumulation capacitance in MOS capacitors, taking into account of the $\mathrm{SiO}_{2}$ interfacial layer. However, on the as-deposited sample, a high value of oxide trapped charge $\left(\mathrm{N}_{\mathrm{ot}}\right)$ of $2.7 \times 10^{12} \mathrm{~cm}^{-2}$ was found. Nevertheless, after the annealing treatment at $800{ }^{\circ} \mathrm{C}$ in $\mathrm{N}_{2}$, the nanolaminated stack showed an improvement of the dielectric properties, since the dielectric constant value increased to 13.4 and the $\mathrm{N}_{\text {ot }}$ value decreased to $1.15 \times 10^{12} \mathrm{~cm}^{-2}$.
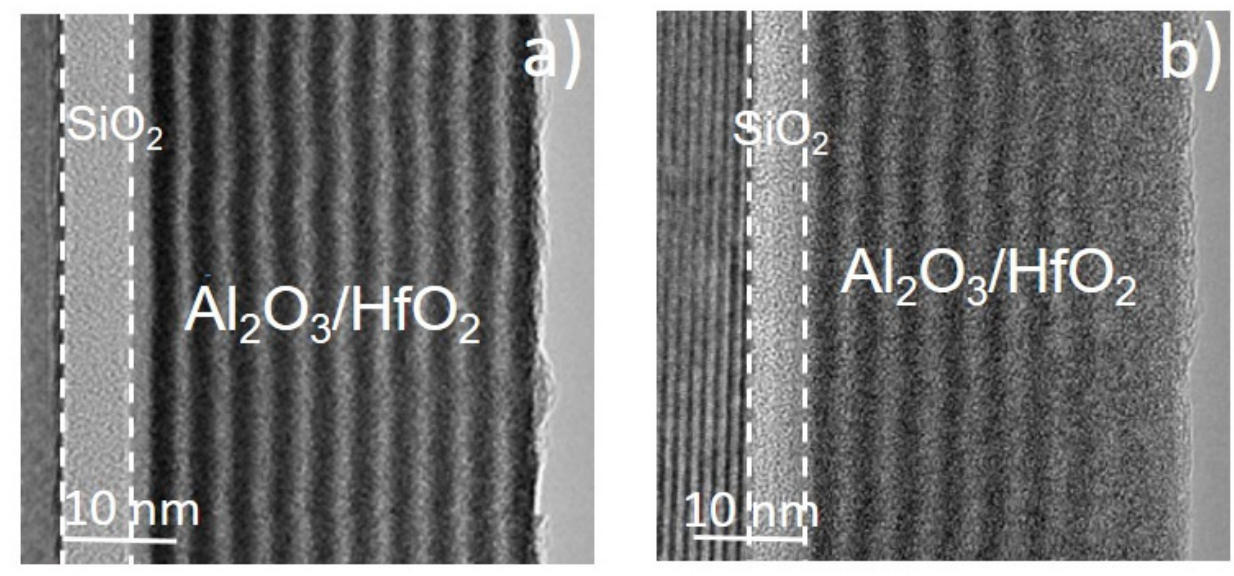

Figure 5. TEM image of (a) as deposited and (b) $800{ }^{\circ} \mathrm{C}$ annealed $\mathrm{Al}_{2} \mathrm{O}_{3} / \mathrm{HfO}_{2}$ nanolaminate, deposited onto $\mathrm{SiO}_{2} / \mathrm{SiC}$ substrate. Reproduced from [63]. Copyright (C) 2020 Authors.

Few other papers have been dedicated to thin films of simple high-k oxides such as $\mathrm{La}_{2} \mathrm{O}_{3}[59,60], \mathrm{Ta}_{2} \mathrm{O}_{5}$ [61], or $\mathrm{TiO}_{2}$ [62], which, when directly grown on $4 \mathrm{H}-\mathrm{SiC}$, showed analogous results as in the case of simple $\mathrm{HfO}_{2}$ oxide. Generally, they demonstrated good dielectric constant values, but their high interface state density and low breakdown voltages made them still far from possible implementation in real devices.

In summary, among the pure high- $\mathrm{k}$ oxides, $\mathrm{Al}_{2} \mathrm{O}_{3}$ thin films represent the best compromise, especially in combination with a very thin $\mathrm{SiO}_{2}$ interfacial layer. Some possible other high- $\mathrm{k}$ bilayers, such as $\mathrm{HfO}_{2} / \mathrm{Al}_{2} \mathrm{O}_{3}$ [64], $\mathrm{Y}_{2} \mathrm{O}_{3} / \mathrm{Al}_{2} \mathrm{O}_{3}$ [65], or $\mathrm{ZrO}_{2} / \mathrm{SiO}_{2}$ [66], exhibited some potentiality, although not many reports have been made available to date, especially regarding devices. 
In regard to dielectric properties, the relevant results on the electrical performances of high-K oxides integrated in SiC MOSFETs are reported in more detail in Section 4.

\subsection{Growth of Amorphous High-k Oxides on GaN-based Materials}

The surfaces of GaN-based materials (GaN, AlGaN, InGaN, etc.) are typically characterized by the presence of large concentrations of defects (e.g., nitrogen vacancies, structural/morphological imperfections, residual contaminations, etc.) that can result in large leakage current and low performance and device reliability. Kerr et al. [67] demonstrated by density functional theory simulations that the defect sites, such as Ga dangling bonds and Ga-Al metal bonds, are responsible for the formation of states in the band gap. These interfacial trap states could be removed by annealing procedures before or after gate dielectric deposition. Moreover, especially from the perspective of high-k gate oxide deposition, the removal of contaminations is crucial for increasing the density of precursor nucleation sites. Hence, pre-deposition surface treatments are needed to improve high-k oxide quality. Systematic studies [68-76] have reported on the effect of several pre-treatments, and the principal cleaning/activation methods have been based on the use of wet chemical solutions $[68-72,77,78]$ or plasma/gas actions [73-76]. Generally, the piranha $\left(\mathrm{H}_{2} \mathrm{O}_{2}: \mathrm{H}_{2} \mathrm{SO}_{4}\right)$ solution is used for the cleaning of carbon contaminations, but some oxidation of the nitride surface can occur $[70,71]$. On the other hand, chloride acid $(\mathrm{HCl})$ solution is efficient for the removal of metallic contaminations (eventually present from device processing) or residual oxygen on the surface. However, chlorine itself could be a residual contamination of the system [70]. Finally, hydrofluoric acid (HF) treatment is effective for the elimination of unwanted native oxide formation but is not efficient for carbon contamination [70,71]. Brennan et al. [71] compared the nucleation efficiency of the Al precursor with/without the cleaning of the surface by sequential use of acetone, methanol, isopropanol, and HF $2 \%$ solution. It was clear, from the results of an XPS study after each ALD cycle, that the decrease in the Ga-O concentration induced by the HF etch resulted in a stronger interaction between the Al precursor and the Ga surface. Nepal et al. [69] compared the effects of three different chemical solutions (i.e., piranha, diluted $\mathrm{HF}$, and diluted $\mathrm{HCl}$ ), finding that: (i) the single $\mathrm{HCl}$ pre-treatment provides 10-30 nm-sized particles, indicating a three-dimensional nucleation; (ii) the HF-based treatments produced an improvement in the electrical behaviour; (iii) the best dielectric properties, in terms of smaller hysteresis and lower density-trap state values, were obtained on the piranha-treated surface. Finally, Schilirò et al. [72] showed a comparison among several chemical solution combinations (i.e., piranha, $\mathrm{HCl} / \mathrm{HF}$, and piranha/HF). In particular, it was shown that, although the $\mathrm{Al}_{2} \mathrm{O}_{3}$ thin films treated with each solution possessed identical structural properties, adherent, uniform, and amorphous, there were some intrinsic differences depending on the adopted surface pre-cleaning. In fact, under a TEM electron beam, the films deposited after piranha treatment showed the formation of polycrystalline grains, while epitaxial layers were formed for samples deposited after HF based treatments. This was an indication that in the case of HF-based treatments, the deposition process occurred on a very clean AlGaN surface, which could act as seed layer for the formation of epitaxial films. Moreover, investigation of the initial growth stages by AFM demonstrated that the smallest three-dimensional grain nucleation resulted in deposition on HF-HCl-treated surfaces, which could ensure a cleaner surface in order to allow ideal layer-by-layer ALD growth.

It could be concluded that the pre-deposition treatments of GaN-based surfaces with $\mathrm{HF}$ cleaning provided $\mathrm{Al}_{2} \mathrm{O}_{3}$ films with the best dielectric properties $[69,71,72]$.

An alternative route to cleaning by chemical solution is represented by "in situ" cleaning process based on $\mathrm{H}_{2} / \mathrm{N}_{2}$ (forming gas) or $\mathrm{NH}_{3}$ plasma actions [68]. The impact of $\mathrm{N}_{2}$ and forming gas on the growth and interfacial characteristics of $\mathrm{Al}_{2} \mathrm{O}_{3}$ on $\mathrm{AlGaN} / \mathrm{GaN}$ heterostructures was explored by Qin et al. [73], who demonstrated by XPS investigation that $C$ contamination was effectively reduced by both $\mathrm{N}_{2}$ and forming gas plasma. The latter also decreased the number of $\mathrm{Ga}-\mathrm{O}$ bonds, improving the $\mathrm{Al}_{2} \mathrm{O}_{3}$ nucleation. In regard to plasma action effects before high- $\mathrm{k}$ deposition, the same group contributed with a large 
variety of studies $[73,75,76]$. In particular, the effects of $\mathrm{O}_{2}, \mathrm{~N}_{2}$, and forming gas plasma annealing were evaluated, comparing the electrical behaviour in terms of interface state density with the results obtained by XPS analyses. The formation of oxynitride bonds (Ga$\mathrm{O}-\mathrm{N}$ ) increased the number of interface defects and that among all the studied treatments, the forming gas action was the most efficient.

In this context, it has to be emphasized that the semiconductor surface preparation and the deposition conditions may induce different insulting behaviours after the first film growth stages. As an example, Schilirò et al. [79] recently reported different behaviour in the early growth stages of $\mathrm{Al}_{2} \mathrm{O}_{3}$ thin films deposited on $\mathrm{AlGaN} / \mathrm{GaN}$ heterostructures by thermal or plasma-enhanced ALD. In particular, they provided evidence that the PEALD process occurred under ideal layer-by-layer growth because of the efficiency of the $\mathrm{O}_{2}$-plasma agent, which acted directly on the Al precursor. On the other hand, the T-ALD approach resulted in a nucleation process of the $\mathrm{Al}_{2} \mathrm{O}_{3}$ film similar to the island-growth model and a higher susceptibility to charge trapping [79].

Summarizing, surface preparation prior to high-k oxide deposition is a crucial issue, including in the case of GaN-based materials, and can be carried out by many procedures. The aim is the cleaning of $\mathrm{C}$ residues, which are detrimental for the oxides' nucleation, and the elimination of Ga-N-O bonds, which are the main centres of interfacial electronic defects. These two issues are generally addressed by non-oxidizing plasma action or by HF treatments.

\section{Epitaxial Growth of High-K Oxides on WBG Semiconductors}

While different oxides have been studied as gate insulators on SiC and GaN [15-19], only some of them can be grown epitaxially on the WBG semiconductor single-crystal surface [23-25,80-84]. The epitaxial growth of high-k oxides on WBG semiconductor substrates can offer some advantages. Generally, the principal improvement is related to better saturation of interface unbonded atoms. In particular, the most commonly used $\mathrm{SiC}$ and $\mathrm{GaN}$ polymorphs for microelectronics applications possess the wurtzite structure, with hexagonal surface atomic arrangements. However, though in principle this strategy can be applied to both $\mathrm{SiC}$ and $\mathrm{GaN}$ technologies, practical studies have been performed mainly on GaN-based substrates. In fact, the few studies of epitaxial high-k materials on $\mathrm{SiC}$ substrates were limited to $\gamma-\mathrm{Al}_{2} \mathrm{O}_{3}$ phase films [80] and direct growth of $\mathrm{NiO}$ thin films by metal organic chemical vapour deposition (MOCVD) [81]. The $\gamma-\mathrm{Al}_{2} \mathrm{O}_{3}$ phase films were initially grown by Tanner et al. [80] by the ALD process as amorphous layers, and the epitaxy on $4 \mathrm{H}-\mathrm{SiC}$ substrate was obtained under a post-annealing crystallization process at a very high $\left(1100^{\circ} \mathrm{C}\right)$ temperature. The epitaxy was observed for the alignment of the $\gamma-\mathrm{Al}_{2} \mathrm{O}_{3}$ (111) planes with the (001) $4 \mathrm{H}-\mathrm{SiC}$ substrate, having a lattice mismatch of about $8.8 \%$. On the basis of the performed reflection high-energy electron diffraction analysis, the (111) $\gamma-\mathrm{Al}_{2} \mathrm{O}_{3}$ oriented films showed quite good structural properties for film thickness up to $20 \mathrm{~nm}$, even though some twinned grains were present. Moreover, upon increasing the film thickness, the crystallization process was no more efficient, and amorphous regions were observed under TEM investigation.

Epitaxial $\mathrm{NiO}$ films, by contrast, have been directly grown onto $4 \mathrm{H}-\mathrm{SiC}$ epilayers at the deposition temperature of $550{ }^{\circ} \mathrm{C}[81,85]$. A high-resolution TEM micrograph of the $\mathrm{NiO} / 4 \mathrm{H}-\mathrm{SiC}$ interface (Figure $6 \mathrm{a}$ ) confirmed the presence of an axially-oriented (111) $\mathrm{NiO}$ film, but a "non-ideal" interface was observed, because a discontinuous amorphous $\mathrm{SiO}_{2}$ layer was detected, probably formed during MOCVD growth. Furthermore, the presence of Moiré fringes generated by the superposition of twinned $\mathrm{NiO}$ grains was observed. The $\mathrm{C}-\mathrm{V}$ characteristics of $\mathrm{NiO} / 4 \mathrm{H}-\mathrm{SiC}$ capacitors (Figure $6 \mathrm{~b}$ ) were used to calculate the dielectric constant, the value of which, at 6.2, was much lower than the theoretical 11.9. This result was justified by the presence of the discontinuous silicon oxide interfacial layer. 

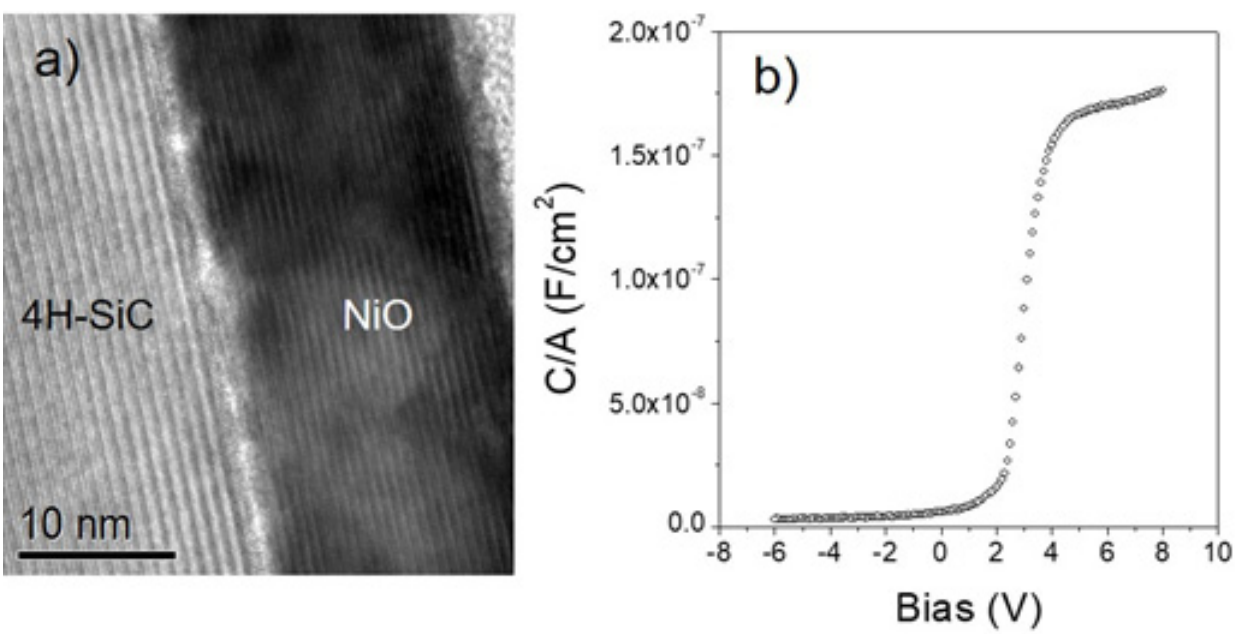

Figure 6. (a) High-resolution cross-section TEM image of a NiO film deposited by MOCVD on 4H-SiC at $500{ }^{\circ} \mathrm{C}$; (b) $\mathrm{C}-\mathrm{V}$ curve acquired on a NiO/4H-SiC MOS capacitor. Reproduced with permission from [81]. Copyright (c) 2013 Elsevier Ltd.

More studies on growing epitaxial oxides have been carried out on GaN-based materials. The materials under investigation comprise some lanthanide oxides, such as gadolinium [82], scandium [83,84], and lanthanum [83] oxides, as well as nickel [23,24,81] and cerium oxides $[25,81]$. The lanthanides oxides possess bixbyite symmetry, while $\mathrm{NiO}$ and $\mathrm{CeO}_{2}$ are face cubic centred (fcc) oxides. However, the (111) planes of the latter two possess a hexagonal oxygen structure, which is suitable for epitaxy with the (0001) GaN superficial planes. Their structural and physical properties are summarized in Table 3.

Table 3. Physical and structural properties of high-k oxides epitaxially grown on GaN.

\begin{tabular}{|c|c|c|c|c|c|}
\hline Oxide & Dielectric Constant & Lattice Constant $(\AA)$ & Mismatch to (0001) GaN (\%) & Deposition Technique & Ref. \\
\hline $\mathrm{Gd}_{2} \mathrm{O}_{3}$ & 9 & 10.813 & 20.1 & MBE & [82] \\
\hline $\mathrm{Sc}_{2} \mathrm{O}_{3}$ & $13-14$ & 9.845 & 9.2 & PVD and MBE & {$[83,84]$} \\
\hline $\mathrm{La}_{2} \mathrm{O}_{3}$ & $18-27$ & 4.211 & 6.5 & MBE & [83] \\
\hline $\mathrm{CeO}_{2}$ & $15-26$ & 5.411 & 6 & MOCVD & {$[25,81]$} \\
\hline $\mathrm{NiO}$ & 11.9 & 4.177 & 5 & Thermal oxidation or MOCVD & {$[23,24,81]$} \\
\hline
\end{tabular}

The epitaxial growth of $\mathrm{Sc}_{2} \mathrm{O}_{3}$ thin films was performed on a GaN substrate at about $700{ }^{\circ} \mathrm{C}$ by the pulsed laser deposition (PLD) technique [84]. Herrero et al. [84] demonstrated that the most critical deposition parameter to obtain perfectly stoichiometric and epitaxial $\mathrm{Sc}_{2} \mathrm{O}_{3}$ thin films was the oxygen partial pressure. In particular, above 50 millitorr oxygen partial pressure, more than one preferential growth direction was observed. The epitaxial growth of $\mathrm{Sc}_{2} \mathrm{O}_{3}$ was also evaluated by Jur et al. [83] by the MBE technique. Their investigation extended to $\mathrm{La}_{2} \mathrm{O}_{3}$, which in principle can provide a dielectric constant of 26 in its hexagonal structure. Nevertheless, $\mathrm{La}_{2} \mathrm{O}_{3}$ growth was demonstrated not to be trivial, since $\mathrm{La}_{2} \mathrm{O}_{3}$ is a hygroscopic material and tends to form an amorphous layer at the interface with the GaN substrates. Nevertheless, the authors demonstrated that it was possible to inhibit the water diffusion by the introduction of a thin $\mathrm{Sc}_{2} \mathrm{O}_{3}$ layer between $\mathrm{GaN}$ and the growing $\mathrm{La}_{2} \mathrm{O}_{3}$ films. The MBE technique was also used for the growth of $\mathrm{Gd}_{2} \mathrm{O}_{3}$ epitaxial gate oxide on an AlGaN/GaN heterostructure [82]. Sakar et al. [82] showed the impact of a $\mathrm{Gd}_{2} \mathrm{O}_{3}$ epitaxial oxide layer on the electrical performance of an HEMT device. $\mathrm{Gd}_{2} \mathrm{O}_{3}$ films were deposited at $650{ }^{\circ} \mathrm{C}$. The authors demonstrated that the $\mathrm{Gd}_{2} \mathrm{O}_{3}$ layer underwent phase transition upon increasing its film thickness. The first layers, up to about $3 \mathrm{~nm}$, possessed hexagonal structure, which changed to monoclinic phase when the thickness of $15 \mathrm{~nm}$ was reached. This phase transformation had a great impact on the electrical 
properties, especially in terms of interface trap density, which showed a minimum value of $2.98 \times 10^{12} \mathrm{~cm}^{-2} \mathrm{eV}^{-1}$ in $\mathrm{Gd}_{2} \mathrm{O}_{3}$ film $2.8 \mathrm{~nm}$ thick. The authors' conclusion was that the epitaxial lattice strain also positively affected the two-dimensional electron gas density at the AlGaN/GaN interface by about $40 \%$.

Nickel and cerium oxides $\left(\mathrm{NiO}\right.$ and $\left.\mathrm{CeO}_{2}\right)$ have also been deposited onto $\mathrm{AlGaN} / \mathrm{GaN}$ systems. The first report on $\mathrm{NiO}$-oriented film as a gate insulating layer in $\mathrm{AlGaN} / \mathrm{GaN}$ devices was related to thermal oxidation of Ni metal layers [86]. In particular, the fabrication process relied on a heating treatment, in the $300-600{ }^{\circ} \mathrm{C}$ temperature range for $5 \mathrm{~min}$ in air ambient, of a $10 \mathrm{~nm}$-thick Ni metal layer. Besides the observation of a colour change from the dark $\mathrm{Ni}$ metal layer to the transparent $\mathrm{NiO}$ film, no details were provided on the structural or compositional characteristics of the formed NiO layers. Generally, the thermal oxidation of Ni metal layers can lead to the formation of voids in the oxide layer and/or of randomly oriented films, since the process initiates at the grain boundaries and then expands in all directions. The growth kinetics of $\mathrm{NiO}$ film seem to depend on the texture and crystallite size of the initial Ni metallic layer [87]. It has been shown that the strong (111) texture of the $\mathrm{Ni}$ layer results in slow $\mathrm{NiO}$ growth. These slow oxidation kinetics are related to the stronger resistance to oxidation of the $\mathrm{Ni}(111)$ planes [88]. Therefore, the $\mathrm{NiO}$ growth proceeds mainly from other crystallographic planes, mostly located at the grain boundaries. Indeed, most of the Ni grains have a (111) texture. This nonuniform growth results in increased surface roughness after oxidation.

The growth of $\mathrm{NiO}$ and $\mathrm{CeO}_{2}$ thin films on $\mathrm{AlGaN} / \mathrm{GaN}$ heterostructures was carried out by MOCVD at $500{ }^{\circ} \mathrm{C}$ [23-25]. TEM analysis demonstrated the formation of $16 \mathrm{~nm}$-thick $\mathrm{NiO}$ (Figure 7a,b) and $20 \mathrm{~nm}$-thick $\mathrm{CeO}_{2}$ (Figure 7c,d), both compact and uniform films. Since no intermediate layers were visible at the interface, the occurrence of any interaction and/or oxidation of the substrate during the growth process was ruled out. Moreover, the (111) NiO planes were perfectly parallel to the (0001) planes of the AlGaN/GaN substrate.
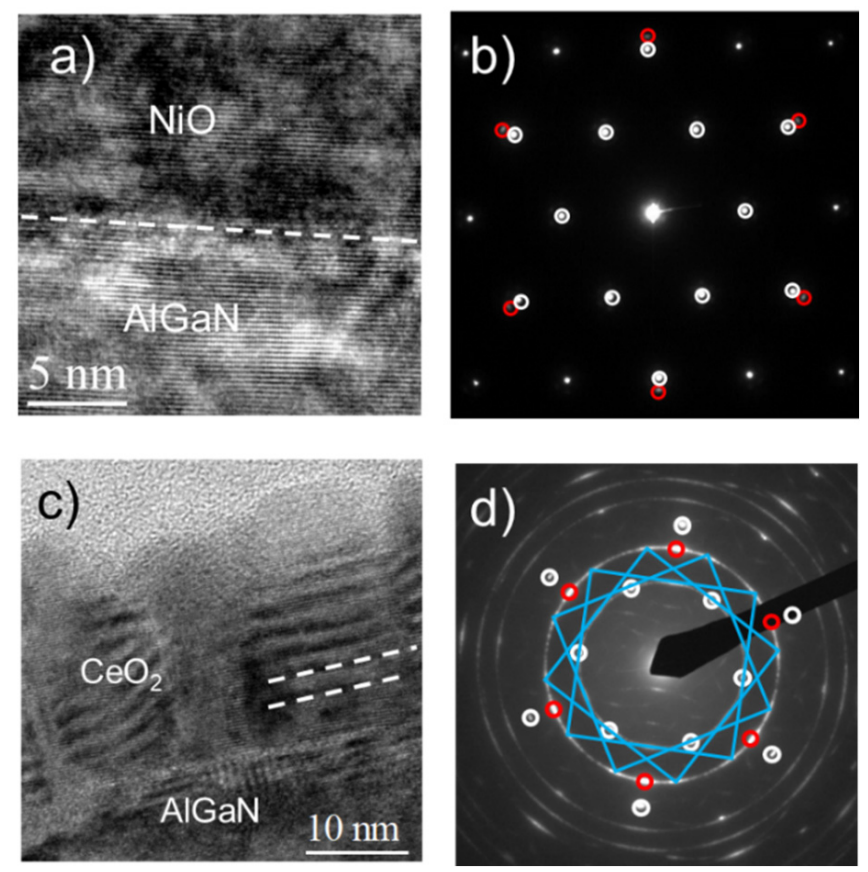

Figure 7. High-magnification cross-section TEM images (a) and in-plane SAED patterns (b) of NiO thin film deposited by MOCVD on AlGaN/GaN heterostructure at $500{ }^{\circ} \mathrm{C}$. High-magnification cross-section TEM image (c) and in-plane SAED patterns (d) of $\mathrm{CeO}_{2}$ thin film deposited by MOCVD on AlGaN/GaN heterostructure at $500{ }^{\circ} \mathrm{C}$. Panel (a): reproduced with permission from [23]. Copyright (C) 2012 AIP Publishing; Panel (d): reproduced with permission from [25]. Copyright (c) 2013 AIP Publishing. 
The selected area electron diffraction (SAED) pattern (Figure $7 \mathrm{~b}$ ) indicated that the external spots related to the $\mathrm{NiO}$ were perfectly aligned to the internal ones from the AlGaN. In particular, the white spots at $2.77 \AA$ and $1.59 \AA$ plane distances could be related to the (100) and (110) $\mathrm{AlGaN} / \mathrm{GaN}$ planes and represented the typical 0001 zone axis pattern for a hexagonal single crystal, while the red spots forming the hexagonal pattern at $1.47 \AA$ can be related to the (220) $\mathrm{NiO}$ plane; thus, only the $111 \mathrm{NiO}$ zone axis is visible. The $\mathrm{NiO}$ spots are perfectly aligned to the $\mathrm{AlGaN} / \mathrm{GaN}$ spots at $1.59 \AA$. Hence, it is possible to conclude that an epitaxial growth of the (111) $\mathrm{NiO}$ planes on the (0001) substrate plane occurred. The occurrence of the epitaxial growth can be explained by considering the threefold symmetry of the (111) $\mathrm{NiO}$, which makes possible an epitaxial relationship between the hexagonal (0001) planes from the AlGaN substrate and the (111) planes of the $\mathrm{NiO}$ film. In particular, the lattice mismatch between the two hexagonal arrangements from the $\mathrm{NiO}$ and $\mathrm{AlGaN}$, calculated from the electron diffraction images, was about 5\%. Moreover, it is worth noting that the XRD peak position of the $\mathrm{NiO}$ (111) reflection was very close to that of bulk $\mathrm{NiO}$, thus indicating that relaxed $\mathrm{NiO}$ thin films with strong diffraction intensity could be obtained under the described operating conditions. Hence, it can be concluded that $\mathrm{NiO}$ deposited samples were epitaxial and stress-free films and possessed excellent interface quality. TEM analysis also defined the structural relationship between the deposited $\mathrm{CeO}_{2}$ films and the $\mathrm{AlGaN} / \mathrm{GaN}$ substrate. A TEM cross-section image showed the formation of $20 \mathrm{~nm}$-thick $\mathrm{CeO}_{2}$ film and an almost perfect film/substrate interface (Figure 7c). The presence of differently oriented grains is evident, as can be deduced by the appearance of Moiré fringes. In-plane SAED was also recorded, and diffraction patterns of three different zone axes were visible. The 0001 zone axis pattern of the substrate is represented by the white circles in Figure 7d. The $\mathrm{CeO}_{2}$ SAED pattern demonstrated that the $\mathrm{CeO}_{2}$ film grew along two different orientations, namely, the (111) and (100) directions. In fact, the 111 zone axis pattern is represented by the red spots lying at $1.93 \AA$ plane distances, and the 100 zone axis pattern is represented by dots lying at the vertex and at the centre of each side of the yellow squares at $1.93 \AA$ and $2.70 \AA$ plane distances, respectively. The $100 \mathrm{CeO}_{2}$ zone axis is represented by three equivalent configurations $30^{\circ}$ rotated in the plane.

Hence, the $\mathrm{NiO}$ films (111) epitaxially grew on (0001) AlGaN/GaN substrate, while the $\mathrm{CeO}_{2}$ film was not a single crystal epitaxial layer but formed by two sets of differently oriented grains (namely, (111)-oriented and (100)-oriented grains) aligned in the (0001) substrate plane of AlGaN.

The electrical characteristics of the oriented $\mathrm{NiO}$ and $\mathrm{CeO}_{2}$ thin films allowed determining their experimental permittivity values. In fact, from the analysis of the $\mathrm{C}-\mathrm{V}$ curves, it was possible to estimate permittivity values of 11.7 and 26 for $\mathrm{NiO}$ and $\mathrm{CeO}_{2}$ films, respectively. These values were very close to those of the $\mathrm{NiO}$ and $\mathrm{CeO}_{2}$ bulk permittivity (11.9 and 26) and properly higher than that of AlGaN alloys. These good values were probably due the oriented growth of the two films, which represented almost an "ideal" bulk system, in contrast to amorphous and/or polycrystalline films, which generally show lower values with respect the bulk materials.

Another key parameter to be considered in dielectric material integration onto WBG semiconductors is the effective density of the trapping states. The maximum of the trapping states determined in the $\mathrm{AlGaN} / \mathrm{GaN}$ metal insulator semiconductor (MIS) diodes were $5 \times 10^{12} \mathrm{~cm}^{-2} \mathrm{eV}^{-1}$ for the $\mathrm{CeO}_{2}$ films and $6 \times 10^{11} \mathrm{~cm}^{-2} \mathrm{eV}^{-1}$ for the $\mathrm{NiO}$ films. The trapping states of the $\mathrm{CeO}_{2}$ were higher than those of the $\mathrm{NiO}$, which could be attributed to the better structural characteristics of the $\mathrm{NiO} / \mathrm{AlGaN}$ interface. While (111) $\mathrm{NiO}$ thin insulating layers seem to be an appealing choice as an epitaxial gate oxide, their integration into a real transistor has not been attempted yet.

\section{Application of High- $\mathrm{k}$ Oxides as Gate Dielectrics in $\mathrm{SiC}$ and GaN Transistors}

As already mentioned in the introduction, most powered electronic devices based on silicon have used silicon dioxide $\left(\mathrm{SiO}_{2}\right)$ as a gate dielectric. However, the use of $\mathrm{SiO}_{2}$ in modern devices based on WBG semiconductors can be a bottleneck for the full exploitation 
of the intrinsic properties of these materials because of the low value of the dielectric permittivity of $\mathrm{SiO}_{2}$.

Figure 8 shows the schematics of common insulated gate transistors based on wide band gap semiconductors ( $\mathrm{SiC}$ and $\mathrm{GaN})$, i.e., a $4 \mathrm{H}-\mathrm{SiC}$ metal oxide semiconductor field effect transistor (MOSFET) (Figure 8a), an $\mathrm{AlGaN} / \mathrm{GaN}$ metal insulator semiconductor high electron mobility transistor (MISHEMT) (Figure $8 b$ ), and a recessed gate hybrid $\mathrm{AlGaN} / \mathrm{GaN}$ MISHEMT (Figure 8c).

(a)

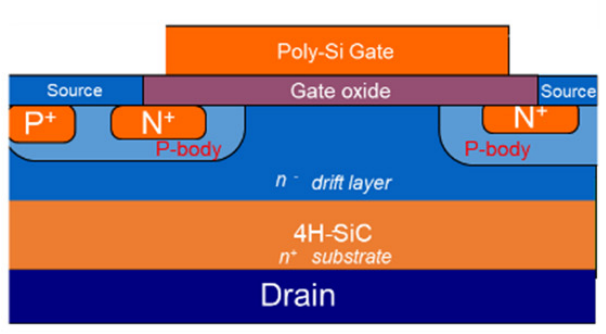

(b)

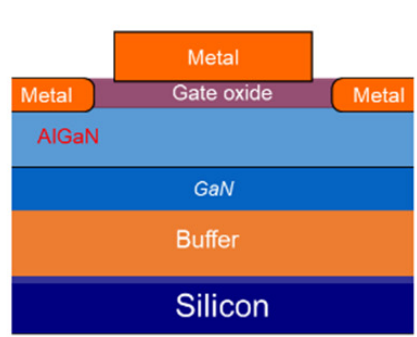

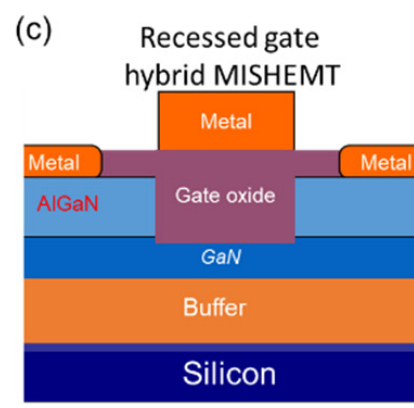

Figure 8. Schematic cross section of (a) a 4H-SiC power MOSFET, (b) an AlGaN/GaN MISHEMT, and (c) a recessed gate hybrid MISHEMT.

A first advantage of using a high- $\mathrm{K}$ dielectric in a power device is related to the distribution of the electric field at the gate dielectric region. In particular, according to Gauss's law, the electric field in a gate dielectric $E_{\text {ins }}$ that is placed on a semiconductor substrate, e.g., in the gate of a transistor, is given as:

$$
\mathrm{E}_{\mathrm{ins}}=\frac{\mathrm{K}_{\mathrm{s}}}{\mathrm{K}_{\mathrm{ins}}} \mathrm{E}_{\mathrm{s}}
$$

where $\kappa_{\mathrm{s}}$ and $\kappa_{\text {ins }}$ are the relative dielectric permittivity values of the semiconductor and insulator, respectively, and $\mathrm{E}_{\mathrm{s}}$ is the electric field in the semiconductor [89].

Considering as an example that the relative dielectric permittivity of $4 \mathrm{H}-\mathrm{SiC}$ is 9.7 while that for $\mathrm{SiO}_{2}$ is 3.9, according to Equation (1), the electric field in the gate oxide is about a factor of 2.5 times that in the semiconductor. Hence, when the critical electric field of $4 \mathrm{H}-\mathrm{SiC}$ is reached, the maximum electric field in the oxide exceeds $9 \mathrm{MV} / \mathrm{cm}$, thus meaning that the insulator is subjected to a significant stress, and the device reliability is penalized. In recognition of this problem, it has been proposed to replace the conventional $\mathrm{SiO}_{2}$ gate dielectric by a high- $\mathrm{k}$ insulator, with a permittivity comparable to that of $\mathrm{SiC}$, so that the electric field in the gate dielectric would become closer to that in the semiconductor. In this way, the maximum electric field in the gate dielectric could be reduced, which should be satisfactory for reliable device operation. Moreover, the changes in the electric field distribution have a strong impact on the drift layer thickness required to sustain the targeted drain bias. In fact, using a high-permittivity gate dielectric allows using the optimal semiconductor drift region for the targeted breakdown, thus minimizing the specific on-resistance of the device.

Moreover, considering always the case of a SiC MOSFET (Figure 8a), the total specific on-resistance $R_{\mathrm{on}, \mathrm{sp}}$ of the device is given by the sum of different contributions [89]:

$$
R_{\text {on }, \text { pp }}=R_{c h}+R_{a}+R_{J F E T}+R_{\text {drift }}+R_{\text {sub }}
$$

where $R_{c h}$ is the channel resistance, $R_{a}$ is the accumulation region resistance, $R_{J F E T}$ is the resistance of the JFET region, $R_{\text {drift }}$ is the resistance of the drift region after the current spreading from the JFET region, and $R_{\text {sub }}$ is the resistance of the n-type doped substrate.

$R_{a}$ and $R_{\text {JFET }}$ can be minimized by appropriately scaling the device layout, and $R_{\text {sub }}$ can be reduced by thinning the substrate. Hence, the control of the channel resistance 
contribution $\mathrm{R}_{\mathrm{ch}}$ is a critical point in $4 \mathrm{H}-\mathrm{SiC}$ MOSFET fabrication. In particular, the channel resistance contribution $R_{c h}$ is given by:

$$
\mathrm{R}_{\mathrm{ch}}=\frac{\left(\mathrm{L}_{\mathrm{ch}} \cdot \mathrm{p}\right)}{\mu_{\mathrm{inv}} \mathrm{C}_{\mathrm{ox}}\left(\mathrm{V}_{\mathrm{G}}-\mathrm{V}_{\mathrm{th}}\right)}
$$

where $\mathrm{p}$ is the pitch of the MOSFET elementary cell, $\mathrm{L}_{\mathrm{ch}}$ is the channel length, $\mu_{\mathrm{inv}}$ is the mobility for electrons in the channel (inversion layer), $\mathrm{C}_{\mathrm{ox}}$ is the specific capacitance of the gate oxide, $\mathrm{V}_{\text {th }}$ is the threshold voltage, and $\mathrm{V}_{\mathrm{G}}$ is the applied gate bias. The gate oxide capacitance term $\mathrm{C}_{\mathrm{ox}}$ increases with the insulator permittivity. Hence, it has a direct impact on the channel resistance and ultimately on the device's total resistance.

As pointed out by theoretical works $[89,90]$, the use of high- $\kappa$ is ideally desirable for future application in trench MOSFET technology [91].

One of the interesting features of the GaN semiconductor and its related $\mathrm{AlGaN}$ alloys is the possibility of growing $\mathrm{AlGaN} / \mathrm{GaN}$ heterostructures. AlGaN/GaN heterostructures are characterized by the presence of a two-dimensional electron gas (2DEG) formed at the interface and possessing a high sheet charge density (in the order of $10^{13} \mathrm{~cm}^{-2}$ ) and a high mobility (above $1000 \mathrm{~cm}^{2} \mathrm{~V}^{-1} \mathrm{~s}^{-1}$ ) [92,93]. Moreover, GaN-based materials have a high critical electric field (above $3 \mathrm{MV} / \mathrm{cm}$ ). Thanks to these unique properties, high-electron mobility transistors (HEMTs) based on AlGaN/GaN heterostructures with excellent performances have been demonstrated in recent years and are suitable candidates for high-frequency applications $[94,95]$. These devices are based on a Schottky barrier at the gate electrode to modulate the channel current. However, particularly for high-voltage applications in which the gate electrode is strongly reverse biased with respect to the drain, a high gate leakage current at the Schottky junction can limit the performance of these transistors [96]. Hence, a dielectric must be introduced under the gate in order to reduce the leakage current, creating a metal-insulator-semiconductor high-electron mobility transistor (MISHEMT), as schematically shown in Figure 8b. In this case, however, the choice of the gate dielectric represents a key issue for improving device performance $[21,97,98]$ and optimizing the parasitic capacitance and the gate leakage current $[19,99]$.

Similarly, the benefits of using high- $\mathrm{k}$ materials on the characteristics of insulated gate transistors in $\mathrm{SiC}$ and $\mathrm{GaN}$ can be understood from the theoretical calculations shown in Figure 9a,b. In particular, Figure 9a shows our calculation of the threshold voltage as a function of the thickness of different high- $\mathrm{K}$ dielectrics for $4 \mathrm{H}-\mathrm{SiC}$ MOSFETs. As the gate dielectric thickness is increased to reduce the gate leakage current, the threshold voltage of the device $\left(\mathrm{V}_{\text {th }}\right)$ also increases. Hence, while an improvement in the off-state characteristics of the MOSFET is achieved, this is accompanied by a degradation in the onstate performance. However, using high- $\mathrm{k}$ dielectrics as insulating gate materials instead of the conventional $\mathrm{SiO}_{2}$, the rate of increase in the threshold voltage with the dielectric thickness is reduced. In this way, the leakage can be reduced, with a minor side effect on the output current.

Figure $9 \mathrm{~b}$ shows the calculation of the threshold voltage of a GaN-based MISHEMT as a function of the gate dielectric layer thickness of different high- $\mathrm{k}$ insulators. In this case, the $\mathrm{V}_{\text {th }}$ of the device is negative because of the inherent normally-on nature of these devices [92]. The negative value of $V_{\text {th }}$ increases with increasing thickness of the gate insulator. However, the rate of this negative shift is reduced with increasing dielectric permittivity [100]. Hence, the use of high- $\mathrm{k}$ gate insulators in GaN-based MISHEMTs is beneficial for reducing the power consumption of the devices. 


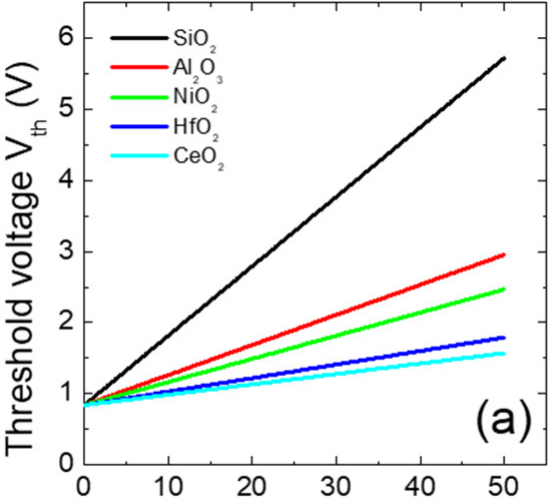

Gate dielectric thickness ( $\mathrm{nm}$ )

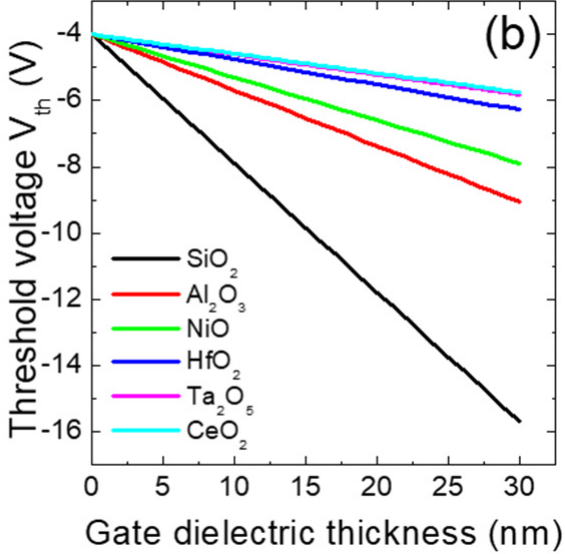

(b)

Figure 9. Calculated threshold voltage of SiC MOSFETs (a) and AlGaN/GaN MISHEMTs (b) as a function of the gate insulator layer thickness for different high- $\kappa$ materials. Panel (b): reproduced with permission from [100]. Copyright @ 2014 WILEY-VCH Verlag GmbH \& Co. KGaA.

\subsection{Binary High- $\kappa$ Oxides in $4 \mathrm{H}-\mathrm{SiC}$ MOSFETs}

Since the band gap for $\mathrm{SiC}$ is three times larger than that for $\mathrm{Si}$, the band offset at the $\mathrm{SiO}_{2} / \mathrm{SiC}$ interface is smaller than that in the $\mathrm{SiO}_{2} / \mathrm{Si}$ system. Hence, in $\mathrm{SiC}$ MOS-based systems, a higher tunnelling current than in $\mathrm{Si}$ is expected for a given oxide thickness [8].

Because of its high permittivity (20), hafnium oxide $\left(\mathrm{HfO}_{2}\right)$ has been widely used in $\mathrm{Si}$ technology. Hence, this material has attracted also the attention of the SiC scientific community. In particular, the investigation started by studying the electronic structure of the $\mathrm{HfO}_{2} / \mathrm{SiC}$ interface [101]. However, it was clear that $\mathrm{HfO}_{2}$ alone is not suitable for $\mathrm{SiC}$ because of the low conduction band offset (in the range $0.5-0.7 \mathrm{eV}$ )) at the $\mathrm{HfO}_{2} / \mathrm{SiC}$ interface, which may not provide an adequate barrier height for electron injection from the substrate [101,102]. Because of the intrinsic limitation of the band alignment, attention moved to the study of the $\mathrm{HfO}_{2} / \mathrm{SiO}_{2} / \mathrm{SiC}$ system [102].

Moreover, other high- $\mathrm{k}$ binary oxides with larger band gaps and more favourable band alignment with $\mathrm{SiC}$, such as $\mathrm{Al}_{2} \mathrm{O}_{3}$ [101], $\mathrm{La}_{2} \mathrm{O}_{3}$ [59,103], and $\mathrm{ZrO}_{2}$ [104,105], have been investigated.

In general, in order to mitigate the fundamental limitations of high-k binary oxides, the introduction of a $\mathrm{SiO}_{2}$ interlayer between the high- $\mathrm{k}$ material and $\mathrm{SiC}$ is often adopted [58,102].

A good survey of the literature on high- $\mathrm{k}$ dielectrics for $\mathrm{SiC}$ was recently reported by Siddiqui et al. [106].

As described before, using high- $\mathrm{k}$ dielectrics in $4 \mathrm{H}-\mathrm{SiC}$ MOS-based devices can be beneficial to fully exploit the properties of the material and reduce the device's on-resistance. However, combined interaction with the $\mathrm{SiOx}$ layer can give further improvements. As an example, high channel mobility in $4 \mathrm{H}-\mathrm{SiC}$ MOSFETs with $\mathrm{Al}_{2} \mathrm{O}_{3}$ gate insulators fabricated at low temperatures by MOCVD $\left(64 \mathrm{~cm}^{2} \mathrm{~V}^{-1} \mathrm{~s}^{-1}\right)$ can be obtained when the $\mathrm{Al}_{2} \mathrm{O}_{3}$ gate insulator is deposited at $190^{\circ} \mathrm{C}$. According to Hino et al. [107], this result could be further improved up to an extremely high field-effect mobility of $284 \mathrm{~cm}^{2} \mathrm{~V}^{-1} \mathrm{~s}^{-1}$ when the $4 \mathrm{H}-\mathrm{SiC}$ MOSFET was fabricated with an ultrathin thermally grown SiOx layer inserted between the $\mathrm{Al}_{2} \mathrm{O}_{3}$ and $\mathrm{SiC}$ interface [107].

On this particular aspect, the impact of a thin $\mathrm{SiO}_{2}$ layer thickness inserted between $\mathrm{Al}_{2} \mathrm{O}_{3}$ and $\mathrm{SiC}$ on the channel mobility in $\mathrm{Al}_{2} \mathrm{O}_{3} / \mathrm{SiC}$ MOSFETs was investigated by Hatayama et al. [108]. They demonstrated that the peak value of the field-effect mobility in $\mathrm{Al}_{2} \mathrm{O}_{3} / \mathrm{SiO}_{2} / \mathrm{SiC}$ MOSFETs could reach $300 \mathrm{~cm}^{2} \mathrm{~V}^{-1} \mathrm{~s}^{-1}$ for an $\mathrm{SiO}_{2}$ thickness of $1 \mathrm{~nm}$. On the other hand, when the $\mathrm{SiO}_{2}$ layer increased up to $2 \mathrm{~nm}$, the field-effect mobility drastically reduced to $40 \mathrm{~cm}^{2} \mathrm{~V}^{-1} \mathrm{~s}^{-1}$ [108], as illustrated in Figure 10 .

Another possible approach is employing a semiconductor surface treatment prior to gate insulator deposition. Lichtenwalner et al. [43] reported the use of a NO annealing at 
1175 or $1100{ }^{\circ} \mathrm{C}$ for $20 \mathrm{~min}$ of a $4 \mathrm{H}-\mathrm{SiC}$ semiconductor in an attempt to control the interface state density $\mathrm{D}_{\text {it. }}$ This procedure allowed obtaining a peak field-effect mobility in $4 \mathrm{H}-\mathrm{SiC}$ MOSFETs of $106 \mathrm{~cm}^{2} \mathrm{~V}^{-1} \mathrm{~s}^{-1}$ using an $\mathrm{Al}_{2} \mathrm{O}_{3}$ film deposited by ALD as gate dielectric with postdeposition annealing at $400{ }^{\circ} \mathrm{C}$ for $30 \mathrm{~s}$.
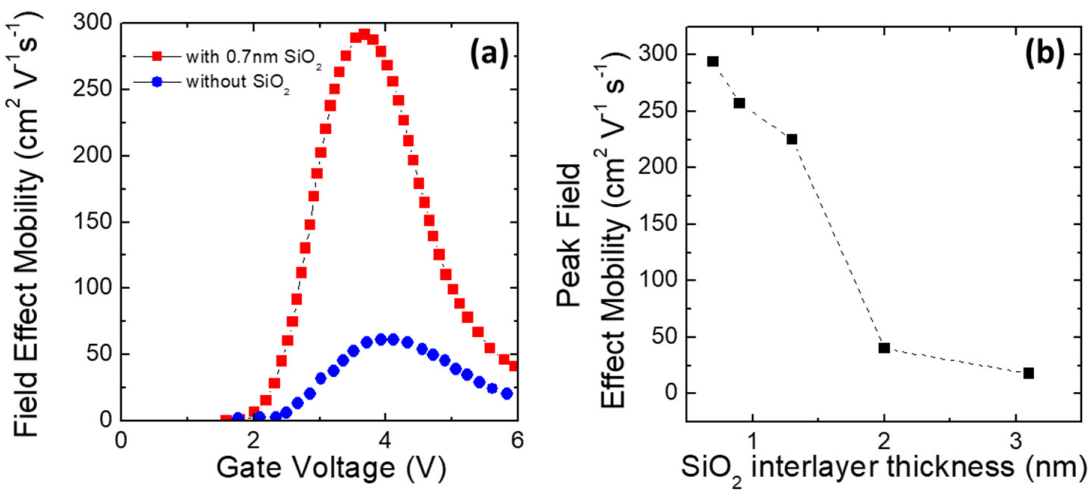

Figure 10. (a) Comparison between the field-effect mobility obtained in 4H-MOSFETs fabricated using $\mathrm{Al}_{2} \mathrm{O}_{3}$ insulators with and without an ultrathin thermally grown $\mathrm{SiOx}$ layer inserted between the $\mathrm{Al}_{2} \mathrm{O}_{3}$ and $\mathrm{SiC}$ interface. (b) Peak value of the field-effect mobility obtained using SiOx layers with different thicknesses. The data are taken from [107,108].

However, a key aspect is the channel mobility at the operative gate bias. In fact, the remarkable peak values of the field-effect mobility are often accompanied by a rapid decrease due to an increase in the gate bias close to the value at which the device should operate. This particular phenomenon can be understood analysing the single components limiting the channel mobility. As an example, a rapid decrease in the field-effect mobility is associated with a dominant phonon-scattering mechanism, while a smooth decrease with an increase in the gate bias is associated with coulombic scattering [109,110]. In particular, Arith et al. [111] demonstrated a process for forming aluminium oxide (by ALD) as a gate insulator in $4 \mathrm{H}-\mathrm{SiC}$ MOSFET that did not involve the insertion or formation of $\mathrm{SiO}_{2}$ at the interface, eliminating traps that may be present in $\mathrm{SiO}_{2}$. This was achieved with hydrogen plasma pre-treatment followed by annealing in forming gas. Hydrogen treatment was effective at reducing $\mathrm{D}_{\mathrm{it}}$ at the interface of aluminium oxide and $\mathrm{SiC}$ without a $\mathrm{SiO}_{2}$ interlayer.

Clearly, because of the large differences in the mobility behaviour of the MOSFETs processed under different conditions, this topic has been strongly debated. In particular, Yoshioka et al. [47] demonstrated optimization of the interface of aluminium oxide and SiC without a $\mathrm{SiO}_{2}$ interlayer, resulting in a low $\mathrm{D}_{\mathrm{it}}$ for the metal oxide semiconductor (MOS) capacitor of $1.7 \times 10^{12} \mathrm{~cm}^{-2} \mathrm{eV}^{-1}$ at $\mathrm{E}_{\mathrm{C}}-\mathrm{E}_{\mathrm{t}}=0.2 \mathrm{eV}$ and a peak field-effect mobility of $57 \mathrm{~cm}^{2} \mathrm{~V}^{-1} \mathrm{~s}^{-1}$ that was quite constant with the variation of the gate bias. Other works have tried to figure out the right combination of semiconductor surface pre-treatments and postdeposition annealing in order to improve the electrical properties of $\mathrm{Al}_{2} \mathrm{O}_{3} / \mathrm{SiC}$ interfaces $[41,46]$.

Other processing steps have been explored to improve the performance of $4 \mathrm{H}-\mathrm{SiC}$ MOSFETs, e.g., by appropriate manipulation of the $\mathrm{SiO}_{2} / \mathrm{SiC}$ interface. In particular, Yang et al. [112] deposited $30 \mathrm{~nm}$ of $\mathrm{SiO}_{2}$ by ALD and subsequently performed a postdeposition annealing (PDA) in a nitrous oxide $\left(\mathrm{N}_{2} \mathrm{O}\right)$ ambient. The highest electron mobility of $26 \mathrm{~cm}^{2} \mathrm{~V}^{-1} \mathrm{~s}^{-1}$ was achieved by performing PDA at $1100{ }^{\circ} \mathrm{C}$ for $40 \mathrm{~s}$. The gate oxide could withstand effective fields up to $6 \mathrm{MV} / \mathrm{cm}$ within a leakage current range of $1 \times 10^{-7} \mathrm{~A} / \mathrm{cm}^{2}$. This value of maximum electric field was small compared to that of thermally grown $\mathrm{SiO}_{2}$, which can typically withstand up to $10 \mathrm{MV} / \mathrm{cm}$. In another work, Yang et al. [113] inserted $1 \mathrm{~nm}$ of lanthanum silicate ( $\mathrm{LaSiOx}$ ) between $\mathrm{ALD}$-deposited $\mathrm{SiO}_{2}$ and $4 \mathrm{H}$-SiC to form a gate stack. Peak mobility of $132.6 \mathrm{~cm}^{2} \mathrm{~V}^{-1} \mathrm{~s}^{-1}$ was found, with three times larger current 
capability compared to gate oxide without $\mathrm{La}_{2} \mathrm{O}_{3}$, but no field oxide data were given. Figure 11 shows a summary of the discussed results.
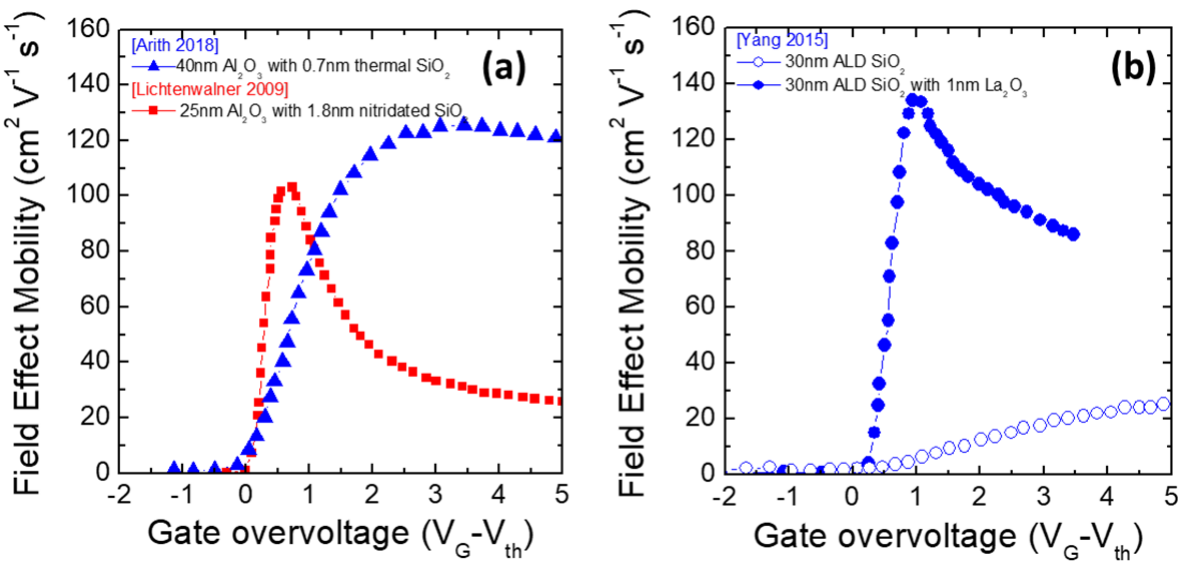

Figure 11. (a) Comparison between the field-effect mobility obtained in 4H-MOSFETs fabricated using $\mathrm{Al}_{2} \mathrm{O}_{3}$ insulators with the insertion of ultrathin thermally grown or nitridated $\mathrm{SiO}_{2}$ layers (b) Comparison between the field-effect mobility obtained in $4 \mathrm{H}-\mathrm{SiC}$ MOSFETs fabricated using $\mathrm{SiO}_{2}$ insulators with the insertion of ultrathin $\mathrm{La}_{2} \mathrm{O}_{3}$ layer. The data are taken from Refs. $[43,111,113]$.

It has to be mentioned that ternary insulators have also been investigated for MOSFET application in $4 \mathrm{H}-\mathrm{SiC}$. In particular, AlON films provided interesting and reliable results both in MOS and MOSFET applications [114-116]. However, ternary elements are not the focus of this review.

Very recently, Jayawardhena et al. [117] pointed out the relevance of the appropriate pre-treatment of the semiconductor to achieve reliable and stable electric characteristics by employing $\mathrm{ALD} \mathrm{Al}_{2} \mathrm{O}_{3}$ films directly in contact to the bare $4 \mathrm{H}-\mathrm{SiC}$ surface with no interlayers. In particular, their best results were obtained with the preparation of a nitrided surface via $\mathrm{NO}$ annealing, i.e., a process known to passivate surface defects, and a hydrogen exposure followed by $\mathrm{Al}_{2} \mathrm{O}_{3}$ deposition on the bare $4 \mathrm{H}-\mathrm{SiC}$ surface [117].

A summary of the most relevant $4 \mathrm{H}-\mathrm{SiC}$ MOSFETs with different high- $\mathrm{k}$ gate dielectrics is reported in Table 4.

Table 4. Survey of literature data on 4H-SiC MOSFETs with different high-k gate dielectrics.

\begin{tabular}{|c|c|c|c|c|c|}
\hline Gate Insulator & Thickness (nm) & $\mathrm{V}_{\mathrm{th}}(\mathrm{V})$ & $\mu_{\mathrm{FE}}\left(\mathrm{cm}^{2} \mathrm{~V}^{-1} \mathrm{~s}^{-1}\right)$ & $D_{i t}\left(\mathrm{~cm}^{-2} \mathrm{eV}\right)$ at $E_{C}-E_{t}=0.2 \mathrm{eV}$ & Ref. \\
\hline $\mathrm{Al}_{2} \mathrm{O}_{3}$ & 35 & 2.8 & 64 & $8 \times 10^{11}$ & [108] \\
\hline $\mathrm{Al}_{2} \mathrm{O}_{3}$ & 33 & $0.5-3$ & 52 & $1 \times 10^{11} \mathrm{~cm}^{-2}$ (integral) & [117] \\
\hline \multirow{4}{*}{$\mathrm{Al}_{2} \mathrm{O}_{3}$ on $\mathrm{SiO}_{2}$} & $35+2$ & 2.8 & 18 & $8 \times 10^{11}$ & [108] \\
\hline & $35+0.7$ & 2.8 & 300 & $5 \times 10^{11}$ & [108] \\
\hline & $40+0.7$ & 2 & 120 & $6 \times 10^{11}$ & [111] \\
\hline & $25+1.8$ & 0.8 & 106 & - & [43] \\
\hline $\mathrm{SiO}_{2}$ on $\mathrm{La}_{2} \mathrm{O}_{3}$ & $30+1$ & 3 & 132 & - & [113] \\
\hline $\mathrm{AlON}$ & $60+10$ & $>0$ & 26.9 & $1 \times 10^{11}$ & [115] \\
\hline
\end{tabular}

\subsection{Binary High- $\kappa$ Oxides for GaN-based MISHEMTs}

Standard AlGaN/GaN MISHEMTs (see Figure $8 \mathrm{~b}$ ) are obtained by insertion of the dielectric between the metal gate and the AlGaN layer. The introduction of the gate dielectric, instead of a standard Schottky barrier gate, gives the advantage of reducing the leakage current that could limit the off-state and the gate voltage swing of the device [118]. A typical example of gate current reduction observed in $\mathrm{HfO}_{2}$ or $\mathrm{CeO}_{2}$ MISHEMTs is displayed in Figure 12a. Indeed, a gate leakage reduction of several orders of magnitude can be observed in both forward and reverse characteristics. This achievement allows a 
higher voltage swing in the device, which in turn results in a higher maximum drain current saturation value $\left(\mathrm{I}_{\mathrm{DSmax}}\right)$. Another great advantage is the very high $\mathrm{I}_{\mathrm{ON}} / \mathrm{I}_{\mathrm{OFF}}$ current ratio. Indeed, high $\mathrm{I}_{\mathrm{ON}} / \mathrm{I}_{\mathrm{OFF}}$ current ratios between $10^{6}$ and $10^{8}$ have been reported in AlGaN/GaN MISHEMTs. In Figure $12 \mathrm{~b}$, the $\mathrm{I}_{\mathrm{ON}} / \mathrm{I}_{\mathrm{OFF}}$ current ratio was plotted as function of the $\mathrm{I}_{\mathrm{DSmax}}$. Interesting, two families of MISHEMTs can be observed depending on the leakage current level. Despite their non-outstanding $\mathrm{I}_{\mathrm{DSmax}}$, some devices can exhibit very high $\mathrm{I}_{\mathrm{ON}} / \mathrm{I}_{\mathrm{OFF}}$ current ratios because of their very low leakage current. On the other hand, in other cases, despite slightly higher leakage current, extraordinary I $\mathrm{DSmax}_{\text {values have }}$ been demonstrated. Table 5 summarizes a survey of the most promising results obtained in normally-on AlGaN/GaN MISHEMTs using different high-k dielectrics. Indeed, not only are $\mathrm{Al}_{2} \mathrm{O}_{3}$ [119-121] and $\mathrm{HfO}_{2}$ [122-125] indicated as suitable dielectrics, but many other gate oxide layers $\left(\mathrm{Y}_{2} \mathrm{O}_{3}\right.$ [126], $\mathrm{HZO}$ [127], $\mathrm{Ta}_{2} \mathrm{O}_{5}$ [128], $\mathrm{La}_{2} \mathrm{O}_{3}$ [125], $\mathrm{ZrO}_{2}$ [129-131], $\mathrm{Gd}_{2} \mathrm{O}_{3}$ [132]) have shown promising results when integrated into GaN HEMT technology.
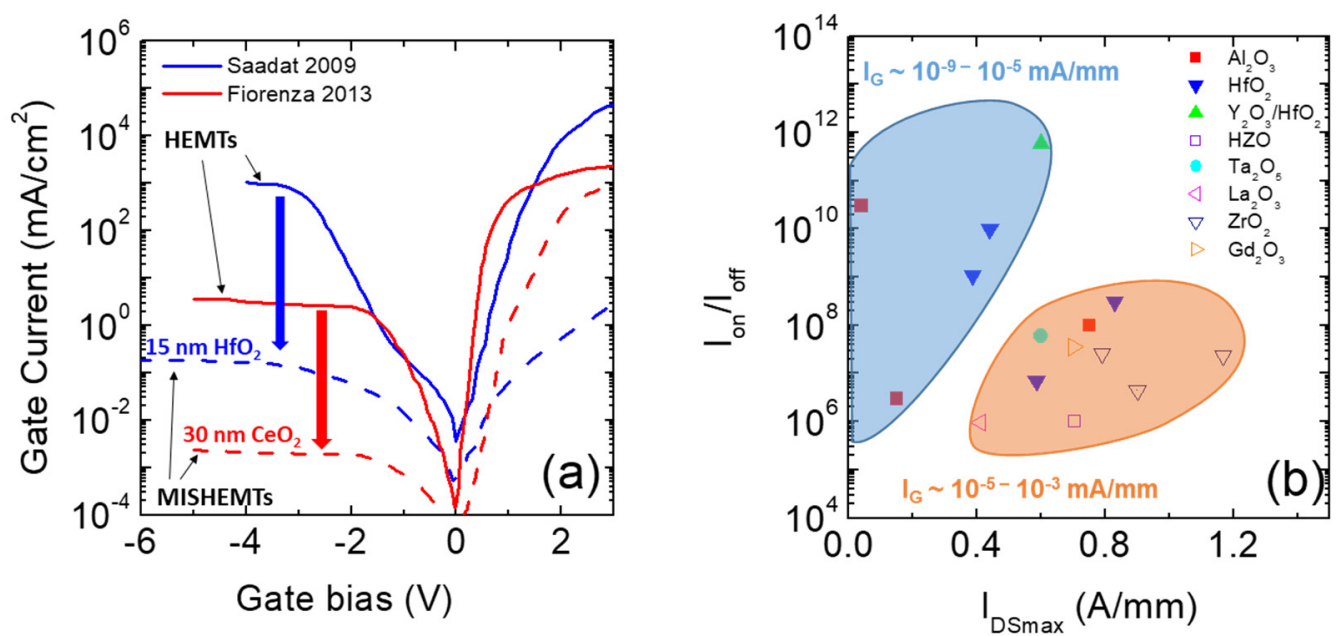

Figure 12. (a) Comparison of the gate current-voltage characteristics of AlGaN/GaN HEMTs (Schottky gate) and MISHEMTs employing $\mathrm{HfO}_{2}$ and $\mathrm{CeO}_{2}$ gate insulators. The data are taken from $[25,118]$. (b) $\mathrm{I}_{\mathrm{ON}} / \mathrm{I}_{\mathrm{OFF}}$ versus $\mathrm{I}_{\mathrm{DSmax}}$ for MISHEMTs using different gate oxides. The data are taken from Table 6 and references therein.

Table 5. Survey of literature data on normally-on AlGaN/GaN MISHEMTs with different high-k gate dielectrics.

\begin{tabular}{|c|c|c|c|c|c|c|}
\hline Dielectric & Thickness (nm) & $\mathrm{V}_{\text {th }}(\mathrm{V})$ & $I_{D \max }(\mathrm{mA} / \mathrm{mm})$ & $\mathrm{I}_{\mathrm{G} \text {-leak }}(\mathrm{mA} / \mathrm{mm})$ & $\mathbf{I}_{\mathrm{ON}} / \mathbf{I}_{\mathrm{OFF}}$ & Ref. \\
\hline \multirow{3}{*}{$\mathrm{Al}_{2} \mathrm{O}_{3}$} & 25 & -7.0 & 150 & $5.0 \times 10^{-5}$ & $3.0 \times 10^{6}$ & [119] \\
\hline & 15 & -7.0 & 750 & $8.0 \times 10^{-5}$ & $1.0 \times 10^{8}$ & [120] \\
\hline & 30 & -8.0 & 40 & $1.0 \times 10^{-8}$ & $3.0 \times 10^{10}$ & [121] \\
\hline \multirow{4}{*}{$\mathrm{HfO}_{2}$} & 20 & -1.1 & 440 & $2.2 \times 10^{-7}$ & $1.0 \times 10^{10}$ & [122] \\
\hline & 12 & -8.0 & 386 & $1.1 \times 10^{-9}$ & $1.1 \times 10^{9}$ & [123] \\
\hline & 23 & -6.0 & 830 & $3.0 \times 10^{-6}$ & $3.0 \times 10^{8}$ & [124] \\
\hline & 8 & -3.7 & 585 & $6.5 \times 10^{-5}$ & $6.9 \times 10^{6}$ & [125] \\
\hline $\mathrm{Y}_{2} \mathrm{O}_{3} / \mathrm{HfO}_{2}$ & $1 / 12$ & -5.0 & 600 & $3.0 \times 10^{-9}$ & $6.0 \times 10^{11}$ & [126] \\
\hline $\mathrm{Ta}_{2} \mathrm{O}_{5}$ & 24 & -9.7 & 600 & $1.0 \times 10^{-5}$ & $6.0 \times 10^{7}$ & [128] \\
\hline $\mathrm{La}_{2} \mathrm{O}_{3}$ & 8 & -2.9 & 409 & $1.0 \times 10^{-4}$ & $9.7 \times 10^{5}$ & [125] \\
\hline \multirow{3}{*}{$\mathrm{ZrO}_{2}$} & 30 & -7 & 1168 & $5.4 \times 10^{-4}$ & $2.3 \times 10^{7}$ & [129] \\
\hline & 10 & -4.2 & 900 & $2.0 \times 10^{-4}$ & $4.5 \times 10^{6}$ & [130] \\
\hline & 10 & -3.9 & 790 & $3.0 \times 10^{-5}$ & $2.6 \times 10^{7}$ & [131] \\
\hline $\mathrm{HfZrO}_{\mathrm{x}}$ & 20 & -12 & 705 & $6.0 \times 10^{-4}$ & $1.0 \times 10^{7}$ & [127] \\
\hline $\mathrm{Gd}_{2} \mathrm{O}_{3}$ & 4 & -6.5 & 700 & $1.0 \times 10^{-6}$ & $3.5 \times 10^{7}$ & [132] \\
\hline
\end{tabular}


A relevant concern often characterizing the behaviour of high- $\mathrm{k}$ binary oxides is the occurrence of charge-trapping phenomena upon bias stress [39], which can be the cause of reliability issues in GaN insulated gate transistors. Nevertheless, the electron trapping inside the $\mathrm{Al}_{2} \mathrm{O}_{3}$ gate insulator in GaN MISHEMTs can be used to intentionally induce a positive shift in the threshold voltage and finally obtain a normally-off operation [121]. In this context, Fiorenza et al. [133] recently studied the temperature stability of these effects, demonstrating the presence of two competitive electron trapping/de-trapping mechanisms in $\mathrm{Al}_{2} \mathrm{O}_{3}$ films, which were likely related to the presence of oxygen vacancies in the material.

Slightly different is the case of normally-off recessed gate hybrid MISHEMTs (see Figure $8 \mathrm{c}$ ). In this case, the $\mathrm{AlGaN}$ layer below the gate region is removed, interrupting the 2DEG channel and resulting in a positive threshold voltage. The gate region is formed by a metal/oxide/GaN (MOS) interface, which requires a positive gate voltage to accumulate electrons at the oxide/GaN interface to restore the channel device. Though this approach seems to solve the crucial issue of normally-off behaviour, the complexity of these systems generates additional concerns. As an example, the lack of a 2DEG channel in the gate region causes a notable increase the channel resistance, leading to a high final on-resistance $\left(\mathrm{R}_{\mathrm{ON}}\right)$ and a reduced $\mathrm{I}_{\mathrm{DSmax}}$. To avoid this problem, it is very important to achieve high electron mobility values [134]. Hence, the oxide/GaN interface quality is clearly a key aspect to ensure a high mobility, as are the morphology of the recessed gate region and the presence of electrically active defects [135]. In this context, the choice of dielectric gate becomes crucial. The use of $\mathrm{SiO}_{2}$ resulted into a poor interface quality displaying fast (interface) and slow (border) traps [136]. Dielectrics such as AlN [137], SiN [138], and their combination [139] have been also investigated as beneficial solutions to passivate surface N-vacancy, especially after recess etching damage in the gate region [140]. However, despite the good quality of the achieved interface and improved electron mobility, it was very difficult to obtain positive threshold voltages $V_{\text {th }}$ well beyond the zero [137]. For these reasons, an increasing number of studies are focused on high-permittivity binary oxide layers for normally-off behaviour of AlGaN/GaN MISHEMTs. Table 6 shows the most promising results obtained in recessed gate hybrid MISHEMTs. ALD-deposited $\mathrm{Al}_{2} \mathrm{O}_{3}$ is one of the most diffused solutions for normally-off recessed gate hybrid MISHEMTs [141-147]. However, an excessive threshold voltage instability has been observed for $\mathrm{Al}_{2} \mathrm{O}_{3}$ gate insulators $[121,148]$. This phenomenon has been attributed to the large number of negative fixed charges incorporated in the gate stack $[148,149]$. As an alternative solution, ALD gate oxides with even higher dielectric constants, such as $\mathrm{HfO}_{2}$ [150] or $\mathrm{ZrO}_{2}$ [151-153], have been investigated for normally-off recessed MISHEMTs. Furthermore, in this case, trapped or fixed charges result in $\mathrm{V}_{\text {th }}$ instability issues. Other opportunities have been found in ternary oxide layers, such as $\mathrm{HfSiO}_{x}$ [154] or $\mathrm{LaHfO}_{\mathbf{x}}$ [155].

Another important challenge in normally-off recessed gate hybrid MISHEMTs is the possibility of obtaining a very high saturation current $\mathrm{I}_{\mathrm{DSmax}}$ with a well positive $\mathrm{V}_{\text {th }}$ value. In Figure 13, experimental values of $\mathrm{I}_{\mathrm{DSmax}}$ are plotted as a function of the threshold voltage $\mathrm{V}_{\text {th }}$. However, the values of $\mathrm{I}_{\mathrm{DSmax}}$ seem to decrease in correspondence with an increase in $\mathrm{V}_{\text {th }}$, thus suggesting the existence of a trade-off between a high output current and a more positive threshold voltage. In this context, a partial recession of the AlGaN barrier layer has also been explored to realize normally-off hybrid MISHEMTs. In this way, a higher 2DEG channel density is obtained. On the other hand, a more uniform and accurate AlGaN etching process is required to obtain a positive threshold voltage and normally-off devices.

Finally, to achieve normally-off behaviour in GaN-based HEMTs, the use of appropriate gate oxides with p-type semiconducting behaviour has been proposed. In fact, similarly to the most diffused p-GaN gate approach [156], the use of a p-type semiconducting oxide can lift up the conduction band at the $\mathrm{AlGaN} / \mathrm{GaN}$ interface, resulting in the depletion of the 2DEG. By applying a positive gate bias $\mathrm{V}_{\mathrm{G}}$, it is possible to realign the conduction band of the structures, restoring the 2DEG and the channel conduction. Among these p-type semiconducting oxides, oxides such as $\mathrm{NiO}$ and $\mathrm{CuO}$ have been taken in consideration for 
normally-off HEMT fabrication [157-159]. The origin of the p-type doping of these oxides is still debated. The existence of negatively charged $\mathrm{Cu}$ or $\mathrm{Ni}$ vacancies and the presence of interstitial oxygen $[160,161]$ have both been considered as possible causes. Moreover, the possibility of epitaxial CVD growth on an $\mathrm{AlGaN}$ or GaN template makes this approach for threshold voltage engineering in GaN technology interesting [23].

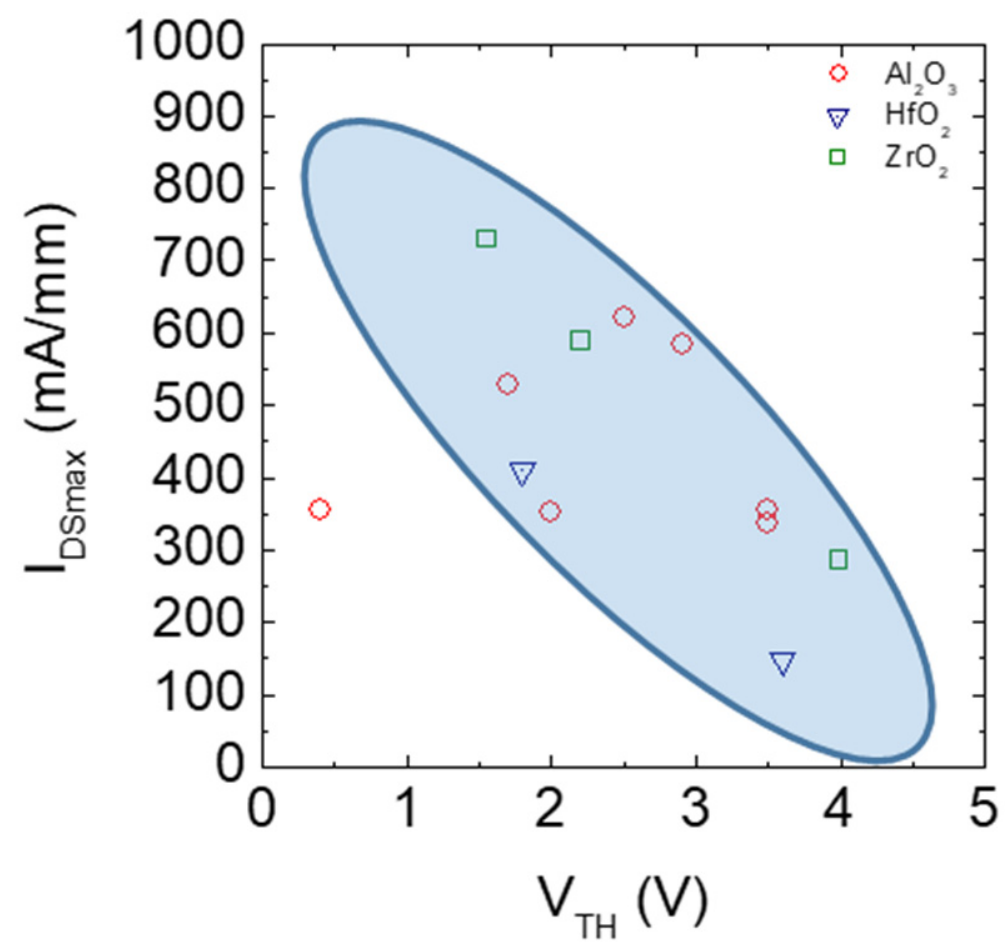

Figure 13. $I_{D S m a x}$ versus $V_{\text {th }}$ value for recessed hybrid MISHEMTs using different high- $\kappa$ binary gate oxides. The data are taken from [141-147,150-153].

Table 6. Survey of literature data on normally-off recessed gate hybrid MISHEMTs with different high-k dielectrics.

\begin{tabular}{|c|c|c|c|c|c|c|}
\hline Dielectric & Thickness (nm) & $\mathrm{V}_{\mathrm{TH}}(\mathrm{V})$ & Mobility $\left(\mathrm{cm}^{2} / \mathrm{Vs}\right)$ & $\mathrm{R}_{\mathrm{ON}}\left(\Omega \mathrm{mm}\right.$ or $\left.\mathrm{m} \Omega \mathrm{cm}^{2}\right)$ & $\mathrm{I}_{\mathrm{DSS}}(\mathrm{mA} / \mathrm{mm})$ & Ref. \\
\hline \multirow{7}{*}{$\mathrm{Al}_{2} \mathrm{O}_{3}$} & 30 & 2 & 225 & $7.8 \Omega \mathrm{mm}$ & 353 & [141] \\
\hline & 38 & 3.5 & 55 & $27 \Omega \mathrm{mm}$ & 336 & [142] \\
\hline & 10 & 1.7 & 251 & $9.8 \Omega \mathrm{mm}$ & 528 & [143] \\
\hline & 20 & 2.9 & 148 & $7.2 \Omega \mathrm{mm}$ & 585 & [144] \\
\hline & 30 & 3.5 & 170 & $9.5 \Omega \mathrm{mm}$ & 355 & [145] \\
\hline & 30 & 2.5 & 192 & $9.6 \Omega \mathrm{mm}$ & 620 & [146] \\
\hline & 23 & 0.4 & 396 & $13.3 \Omega \mathrm{mm}$ & 356 & [147] \\
\hline \multirow{2}{*}{$\mathrm{HfO}_{2}$} & \multirow{2}{*}{30} & 1.8 (partial recessed) & 876 & $5.2 \mathrm{~m} \Omega \mathrm{cm}^{2}$ & 411 & \multirow{2}{*}{ [150] } \\
\hline & & 3.6 (total recessed) & 118 & $12.2 \mathrm{~m} \Omega \mathrm{cm}^{2}$ & 146 & \\
\hline $\mathrm{HfSiO}_{x}$ & 15 & 2.2 & 520 & $10.1 \Omega \mathrm{mm}$ & 519 & [154] \\
\hline $\mathrm{LaHfO}_{x}$ & 8 & 0.35 & & $9.4 \Omega \mathrm{mm}$ & 648 & {$[144]$} \\
\hline \multirow{3}{*}{$\mathrm{ZrO}_{2}$} & 20 & 3.99 & 210 & $24 \Omega \mathrm{mm}$ & 286 & [151] \\
\hline & 23 & 2.2 (partial recessed) & 850 & $9.2 \Omega \mathrm{mm}$ & 590 & [152] \\
\hline & 16 & 1.55 (partial recessed) & 1450 & $7.1 \Omega \mathrm{mm}$ & 730 & [153] \\
\hline
\end{tabular}

\section{Conclusions}

High-permittivity binary oxides for silicon carbide ( $\mathrm{SiC}$ ) and gallium nitride (GaN) electronic devices have attracted significant interest in the last decade because of the potential benefit they can bring in the device performances. In particular, special attention has been placed on the most suitable deposition techniques for their synthesis and on their implementation in real device fabrication, in which all the processes must be compatible with industrial environments and scalable to large areas. Surely the most widely inves- 
tigated binary oxide is $\mathrm{Al}_{2} \mathrm{O}_{3}$, as well as its combination with $\mathrm{HfO}_{2}$ and other materials. In fact, $\mathrm{Al}_{2} \mathrm{O}_{3}$ provides a good compromise among all the basic physical properties to be fulfilled by the gate dielectric for wide band gap semiconductors, namely, a dielectric constant close to that of the semiconductor, a large band gap, an appropriate band offset, a high critical electrical field, and good thermal stability. On the other hand, $\mathrm{HfO}_{2}$ and other oxides possess higher dielectric constants than $\mathrm{Al}_{2} \mathrm{O}_{3}$, but their band alignments and crystallization temperatures represent a concern in application. The most affirmed method for their synthesis has been demonstrated to be the ALD approach, which can be considered the deposition technique of choice for the fabrication of very thin films with high uniformity and conformal growth on large areas. All these capabilities render ALD as very appealing for industrial implementation. In this context, beyond the fundamental study on the impact of the deposition parameters on the films' properties, the pre- and post-deposition conditions are relevant features for the development of a reliable high- $\kappa$ technology for $\mathrm{SiC}$ and $\mathrm{GaN}$. Cleaning treatments before high- $\mathrm{k}$ thin film deposition, e.g., based on wet chemical solutions are the most suitable approach for both $\mathrm{SiC}$ and $\mathrm{GaN}$ substrates in order to limit the creation of interface defects. In spite of the "gentle" nature of the wet cleaning, interface states, as well as fixed charges within the binary oxides, still represent a great concern in practical applications. Hence, post-deposition and post-metallization annealing treatments need to be optimized in order to achieve the desired device performance. A common problem in $\mathrm{SiC}$ technology is the formation of an uncontrolled $\mathrm{SiOx}$ layer at the interface as well as residual carbon. Hence, the intentional $\mathrm{Al}_{2} \mathrm{O}_{3} / \mathrm{SiO}_{2}$ combination has been proposed as a possible solution, although the presence of the $\mathrm{SiO}_{2}$ interfacial layer partially reduces the advantage offered by the high- $\mathrm{K} \mathrm{Al}_{2} \mathrm{O}_{3}$. For that reason, the search for other material combinations and/or post-deposition treatments limiting the interfacial interaction has become mandatory.

In regard to GaN-based devices, the implementation of $\mathrm{Al}_{2} \mathrm{O}_{3}$ thin films is also the most investigated and promising solution. The interaction at the interface is limited to a partial oxidation of the substrate, which in turn might be source of electrically active defects when oxynitride bonds are present. In this case, the epitaxial growth of crystalline oxides has also been widely explored as a possible route to gate insulation in GaN-based devices, considering other oxides, such as lanthanide oxides $\left(\mathrm{Gd}_{2} \mathrm{O}_{3}, \mathrm{Sc}_{2} \mathrm{O}_{3}\right.$, and $\left.\mathrm{La}_{2} \mathrm{O}_{3}\right)$ or $\mathrm{NiO}$ and $\mathrm{CeO}_{2}$. However, the main limitations of the epitaxial oxides' implementation are the number of structural defects occurring after the initial layers and the presence of preferential leakage current paths at the grain boundaries.

In terms of practical device application, high- $\mathrm{k}$ binary oxides have already been implemented in both $4 \mathrm{H}-\mathrm{SiC}$ MOSFETs and GaN-based MISHEMTs, with $\mathrm{Al}_{2} \mathrm{O}_{3}$ being the most widely used system. In this case, while promising results in terms of channel mobility and $\mathrm{R}_{\mathrm{ON}}$ have been reported, charge-trapping effects occurring in these oxides remain a limiting factor that has to be addressed by appropriate surface preparation techniques and post-annealing conditions. In particular, the integration of high- $\mathrm{k}$ oxides as gate insulators in $4 \mathrm{H}-\mathrm{SiC}$ MOSFETs will require optimization of the process flow, with particular attention to the thermal budget required for ohmic contact formation, which must be compatible with the crystallization temperature of the oxide.

Author Contributions: Conceptualization, R.L.N. and F.R.; methodology, P.F., G.G. and E.S.; formal analysis, P.F., G.G. and E.S.; investigation, E.S., P.F. and G.G.; resources, E.S.; data curation, E.S.; writing-original draft preparation, R.L.N., P.F. and G.G.; writing-review and editing, R.L.N. and F.R.; visualization, P.F. and G.G.; supervision, R.L.N. and F.R.; project administration, F.R.; funding acquisition, F.R. All authors have read and agreed to the published version of the manuscript.

Funding: This work was partially funded by the ECSEL-JU project WInSiC4AP (Wide Band Gap Innovative $\mathrm{SiC}$ for Advanced Power)-grant agreement no. 737483 and the national project EleGaNTe (Electronics on GaN-based Technologies)_PON ARS01_01007. Moreover, the authors would like to acknowledge the European project GaN4AP (GaN for Advanced Power Applications)—grant agreement no. 101007310 for funding part of their current GaN activities. 
Data Availability Statement: The data that support the findings of this study are available from the corresponding author upon reasonable request.

Acknowledgments: The authors would like to acknowledge their colleagues at CNR-IMM: F. Giannazzo and M. Vivona, for the fruitful discussions and contributions in SiC and GaN experiments, and S. Di Franco and C. Bongiorno, for the precious technical support during device fabrication and TEM analyses. M. Saggio and F. Iucolano from STMicroelectronics are greatly acknowledged for their fruitful collaboration on wide band gap semiconductor research activities. The authors also thank Graziella Malandrino of the Department of Chemistry, University of Catania, for the fruitful collaboration in the realization of $\mathrm{NiO}$ and $\mathrm{CeO}_{2}$ gate dielectrics by MOCVD.

Conflicts of Interest: The authors declare no conflict of interest.

\section{References}

1. Bose, K.B. Power Electronics-An Emerging Technology. IEEE Trans. Ind. Electr. 1989, 36, 403-412. [CrossRef]

2. Brunco, D.P.; De Jaeger, B.; Eneman, G.; Mitard, J.; Hellings, G.; Satta, A.; Terzieva, V.; Souriau, L.; Leys, F.E.; Pourtois, G.; et al. Germanium MOSFET Devices: Advances in Materials Understanding, Process Development, and Electrical Performance. J. Electrochem. Soc. 2008, 155, H552-H561. [CrossRef]

3. Wong, H.-S.P. Beyond the conventional transistor. IBM J. Res. Dev. 2002, 46, 133-168. [CrossRef]

4. Ostling, M.; Ghandi, R.; Zetterling, C.-M. SiC power devices Present status, applications and future perspective. In Proceedings of the 2011 IEEE 23rd International Symposium on Power Semiconductor Devices and ICs, San Diego, CA, USA, 23-26 May 2011; IEEE: Piscataway, NJ, USA, 2011; pp. 10-15.

5. Roccaforte, F.; Fiorenza, P.; Greco, G.; Nigro, R.L.; Giannazzo, F.; Iucolano, F.; Saggio, M. Emerging trends in wide band gap semiconductors ( $\mathrm{SiC}$ and $\mathrm{GaN}$ ) technology for power devices. Microelectron. Eng. 2018, 187-188, 66-77. [CrossRef]

6. Chen, K.J.; Haberlen, O.; Lidow, A.; Tsai, C.L.; Ueda, T.; Uemoto, Y.; Wu, Y. GaN-on-Si Power Technology: Devices and Applications. IEEE Trans. Electron Devices 2017, 64, 779-795. [CrossRef]

7. Roccaforte, F.; Fiorenza, P.; Nigro, R.L.; Giannazzo, F.; Greco, G. Physics and technology of gallium nitride materials for power electronics. Riv. Nuovo Cim. 2018, 41, 625-681.

8. Kimoto, T.; Cooper, J. Fundamentals of Silicon Carbide Technology: Growth, Characterization, Devices and Applications; JohnWiley \& Sons: Hoboken, NJ, USA, 2014.

9. Roccaforte, F.; Leszczynski, M. Introduction to Gallium Nitride Properties and Applications. In Nitride Semiconductor Technology: Power Electronics and Optoelectronic Devices, 1st ed.; Roccaforte, F., Leszczyński, M., Eds.; Wiley-VCH Verlag: Weinheim, Germany; GmbH \& Co. KGaA: Lippstadt, Germany, 2020; pp. 1-39.

10. Saggio, M.; Guarnera, A.; Zanetti, E.; Rascunà, S.; Frazzetto, A.; Salinas, D.; Giannazzo, F.; Fiorenza, P.; Roccaforte, F. Industrial Approach for Next Generation of Power Devices Based on 4H-SiC. Mater. Sci. Forum 2015, 821-823, 660-666. [CrossRef]

11. Arulkumaran, S.; Egawa, T.; Ishikawa, H.; Jimbo, T.; Sano, Y. Surface passivation effects on AlGaN/GaN high-electron-mobility transistors with $\mathrm{SiO}_{2}, \mathrm{Si}_{3} \mathrm{~N}_{4}$, and silicon oxynitride. Appl. Phys. Lett. 2004, 84, 613-615. [CrossRef]

12. Nakano, Y.; Jimbo, T. Interface properties of $\mathrm{SiO}_{2} / \mathrm{n}-\mathrm{GaN}$ metal-insulator-semiconductor structures. Appl. Phys. Lett. 2002, 80, 4756-4758. [CrossRef]

13. Cook, T.E.; Fulton, C.C.; Mecouch, W.; Davis, R.; Lucovsky, G.; Nemanich, R.J. Band offset measurements of the $\mathrm{Si}_{3} \mathrm{~N}_{4} / \mathrm{GaN}$ (0001) interface. J. Appl. Phys. 2003, 94, 3949-3954. [CrossRef]

14. Placidi, M.; Constant, A.; Fontserè, A.; Pausas, E.; Cortes, I.; Cordier, Y.; Mestres, N.; Pérez, R.; Zabala, M.; Millán, J.; et al. Deposited Thin $\mathrm{SiO}_{2}$ for Gate Oxide on n-Type and p-Type GaN. J. Electrochem. Soc. 2010, 157, H1008-H1013. [CrossRef]

15. Schlom, D.G.; Guha, S.; Datta, S. Gate Oxides Beyond $\mathrm{SiO}_{2}$. MRS Bull. 2008, 33, 1017-1025. [CrossRef]

16. Kingon, A.I.; Maria, J.-P.; Streiffer, S.K. Alternative dielectrics to silicon dioxide for memory and logic devices. Nature 2000, 406, 1032-1038. [CrossRef] [PubMed]

17. Wallace, R.M.; Wilk, G.D. High-k dielectric material for microelectronics. Critic. Rev. Solid State Mater. Sci. 2003, 28, 231-285. [CrossRef]

18. Wilk, G.D.; Wallace, R.; Anthony, J.M. High-k gate dielectrics: Current status and materials properties considerations. J. Appl. Phys. 2001, 89, 5243-5275. [CrossRef]

19. Roccaforte, F.; Fiorenza, P.; Greco, G.; Vivona, M.; Nigro, R.L.; Giannazzo, F.; Patti, A.; Saggio, M. Recent advances on dielectrics technology for SiC and GaN power devices. Appl. Surf. Sci. 2014, 301, 9-18. [CrossRef]

20. Gaskins, J.T.; Hopkins, P.E.; Merrill, D.R.; Bauers, S.R.; Hadland, E.; Johnson, D.C.; Koh, D.; Yum, J.H.; Banerjee, S.; Nordell, B.J.; et al. Review-Investigation and Review of the Thermal, Mechanical, Electrical, Optical, and Structural Properties of Atomic Layer Deposited High-kDielectrics: Beryllium Oxide, Aluminum Oxide, Hafnium Oxide, and Aluminum Nitride. ECS J. Solid State Sci. Technol. 2017, 6, N189-N208. [CrossRef]

21. Ye, P.D.; Yang, B.; Ng, K.K.; Bude, J.; Wilk, G.D.; Halder, S.; Hwang, J.C.M. GaN metal-oxide-semiconductor high-electronmobility-transistor with atomic layer deposited $\mathrm{Al}_{2} \mathrm{O}_{3}$ as gate dielectric. Appl. Phys. Lett. 2005, 86, 63501. [CrossRef]

22. Yue, Y.; Hao, Y.; Zhang, J.; Ni, J.; Mao, W.; Feng, Q.; Liu, L. AlGaN/GaN MOS-HEMT with $\mathrm{HfO}_{2}$ Dielectric and $\mathrm{Al}_{2} \mathrm{O}_{3}$ Interfacial Passivation Layer Grown by Atomic Layer Deposition. IEEE Electron Device Lett. 2008, 29, 838-840. [CrossRef] 
23. Roccaforte, F.; Greco, G.; Fiorenza, P.; Raineri, V.; Malandrino, G.; Nigro, R.L. Epitaxial NiO gate dielectric on AlGaN/GaN heterostructures. Appl. Phys. Lett. 2012, 100, 63511. [CrossRef]

24. Fiorenza, P.; Greco, G.; Giannazzo, F.; Nigro, R.L.; Roccaforte, F. Poole-Frenkel emission in epitaxial nickel oxide on AlGaN/GaN heterostructures. Appl. Phys. Lett. 2012, 101, 172901. [CrossRef]

25. Fiorenza, P.; Greco, G.; Fisichella, G.; Roccaforte, F.; Malandrino, G.; Nigro, R.L. High permittivity cerium oxide thin films on AlGaN/GaN heterostructures. Appl. Phys. Lett. 2013, 103, 112905. [CrossRef]

26. Milanov, A.P.; Xu, K.; Cwik, S.; Parala, H.; Arcos, T.D.L.; Becker, H.-W.; Rogalla, D.; Cross, R.; Paul, S.; Devi, A. Sc $\mathrm{O}_{3}, \mathrm{Er}_{2} \mathrm{O}_{3}$, and $\mathrm{Y}_{2} \mathrm{O}_{3}$ thin films by MOCVD from volatile guanidinate class of rare-earth precursors. Dalton Trans. 2012, 41, 13936-13947. [CrossRef] [PubMed]

27. Chen, J.-J.; Gila, B.P.; Hlad, M.; Gerger, A.; Ren, F.; Abernathy, C.R.; Pearton, S. Band offsets in the $\mathrm{Sc}_{2} \mathrm{O}_{3} / \mathrm{GaN}$ heterojunction system. Appl. Phys. Lett. 2006, 88, 142115. [CrossRef]

28. Prokofiev, A.; Shelykh, A.; Melekh, B. Periodicity in the band gap variation of $\operatorname{Ln}_{2} X_{3}(X=O, S$, Se) in the lanthanide series. $J$. Alloy. Compd. 1996, 242, 41-44. [CrossRef]

29. Fanciulli, M.; Scarel, G. Rare Earth Oxide Thin Films; Springer: Berlin/Heidelberg, Germany, 2007.

30. Fiedler, A.; Schewski, R.; Galazka, Z.; Irmscher, K. Static Dielectric Constant of $\beta-\mathrm{Ga}_{2} \mathrm{O}_{3}$ Perpendicular to the Principal Planes (100), (010), and (001). ECS J. Solid State Sci. Technol. 2019, 8, Q3083-Q3085. [CrossRef]

31. Kääriäinen, T.; Cameron, D.; Kääriäinen, M.L.; Sherman, A. Atomic Layer Deposition, Principles Characteristics and Nanotechnolody Applications; Scrivener, M., Carmical, P., Eds.; John Wiley \& Sons: Hoboken, NJ, USA, 2013.

32. Ahvenniemi, E.; Akbashev, A.R.; Ali, S.; Bechelany, M.; Berdova, M.; Boyadjiev, S.; Cameron, D.C.; Chen, R.; Chubarov, M.; Cremers, V.; et al. Review Article: Recommended reading list of early publications on atomic layer deposition-Outcome of the Virtual Project on the History of ALD. J. Vac. Sci. Technol. A Vac. Surf. Film. 2017, 35, 10801. [CrossRef]

33. Shukla, M.; Dutta, G.; Mannam, R.; DasGupta, N. Electrical properties of reactive-ion-sputtered $\mathrm{Al}_{2} \mathrm{O}_{3}$ on $4 \mathrm{H}-\mathrm{SiC}$. Thin Solid Film. 2016, 607, 1-6. [CrossRef]

34. Paskaleva, A.; Ciechonski, R.R.; Syväjärvi, M.; Atanassova, E.; Yakimova, R. Electrical behavior of 4H-SiC metal-oxidesemiconductor structures with $\mathrm{Al}_{2} \mathrm{O}_{3}$ as gate dielectric. J. Appl. Phys. 2005, 97, 124507. [CrossRef]

35. Fiorenza, P.; Vivona, M.; Di Franco, S.; Smecca, E.; Sanzaro, S.; Alberti, A.; Saggio, M.; Roccaforte, F. Properties of $\mathrm{Al}_{2} \mathrm{O}_{3}$ thin films deposited on $4 \mathrm{H}-\mathrm{SiC}$ by reactive ion sputtering. Mater. Sci. Semicond. Process. 2019, 93, 290-294. [CrossRef]

36. Khosa, R.Y.; Thorsteinsson, E.B.; Winters, M.; Rorsman, N.; Karhu, R.; Hassan, J.U.; Sveinbjörnsson, E.Ö. Electrical characterization of amorphous $\mathrm{Al}_{2} \mathrm{O}_{3}$ dielectric films on n-type $4 \mathrm{H}-\mathrm{SiC}$. AIP Adv. 2018, 8, 25304. [CrossRef]

37. Wolborski, M.; Bakowski, M.; Ortiz, A.; Pore, V.; Schöner, A.; Ritala, M.; Leskelä, M.; Hallén, A. Characterisation of the $\mathrm{Al}_{2} \mathrm{O}_{3}$ films deposited by ultrasonic spray pyrolysis and atomic layer deposition methods for passivation of $4 \mathrm{H}-\mathrm{SiC}$ devices. Microelectron. Reliab. 2006, 46, 743-755. [CrossRef]

38. Huang, S.-W.; Hwu, J.-G. Ultrathin Aluminum Oxide Gate Dielectric on N-Type 4H-SiC Prepared by Low Thermal Budget Nitric Acid Oxidation. IEEE Trans. Electron Devices 2004, 51, 1877-1882. [CrossRef]

39. Schilirò, E.; Nigro, R.L.; Fiorenza, P.; Roccaforte, F. Negative charge trapping effects in $\mathrm{Al}_{2} \mathrm{O}_{3}$ films grown by atomic layer deposition onto thermally oxidized 4H-SiC. AIP Adv. 2016, 6, 75021. [CrossRef]

40. Schilirò, E.; Fiorenza, P.; Di Franco, S.; Bongiorno, C.; Saggio, M.; Roccaforte, F.; Nigro, R.L. Effect of $\mathrm{SiO}_{2}$ interlayer on the properties of $\mathrm{Al}_{2} \mathrm{O}_{3}$ thin films grown by plasma enhanced atomic layer deposition on $4 \mathrm{H}-\mathrm{SiC}$ substrates. Phys. Status Solidi 2016, 214, 1600365. [CrossRef]

41. Tanner, C.M.; Perng, Y.-C.; Frewin, C.L.; Saddow, S.E.; Chang, J.P. Electrical performance of $\mathrm{Al}_{2} \mathrm{O}_{3}$ gate dielectric films deposited by atomic layer deposition on 4H-SiC. Appl. Phys. Lett. 2007, 91, 203510. [CrossRef]

42. Avice, M.; Grossner, U.; Pintilie, I.; Svensson, B.G.; Servidori, M.; Nipoti, R.; Nilsen, O.; Fjellvåg, H. Electrical properties of $\mathrm{Al}_{2} \mathrm{O}_{3} / 4 \mathrm{H}-\mathrm{SiC}$ structures grown by atomic layer chemical vapor deposition. J. Appl. Phys. 2007, 102, 54513. [CrossRef]

43. Lichtenwalner, D.J.; Misra, V.; Dhar, S.; Ryu, S.-H.; Agarwal, A. High-mobility enhancement-mode $4 \mathrm{H}-\mathrm{SiC}$ lateral field-effect transistors utilizing atomic layer deposited $\mathrm{Al}_{2} \mathrm{O}_{3}$ gate dielectric. Appl. Phys. Lett. 2009, 95, 152113. [CrossRef]

44. Cheong, K.Y.; Moon, J.H.; Kim, H.J.; Bahng, W.; Kim, N.-K. Analysis of current conduction mechanisms in atomic-layer-deposited $\mathrm{Al}_{2} \mathrm{O}_{3}$ gate on $4 \mathrm{H}$ silicon carbide. Appl. Phys. Lett. 2007, 90, 162113. [CrossRef]

45. Kern, W.; Puotinen, D.P. Cleaning Solutions Based on Hydrogen Peroxide for use in Silicon Semiconductor Technology. RCA Rev. 1970, 31, 187.

46. Suvanam, S.S.; Usman, M.; Martin, D.; Yazdi, M.G.; Linnarsson, M.K.; Tempez, A.; Gotelid, M.; Hallen, A. Improved interface and electrical properties of atomic layer deposited $\mathrm{Al}_{2} \mathrm{O}_{3} / 4 \mathrm{H}-\mathrm{SiC}$. Appl. Surf. Sci. 2018, 433, 108-115. [CrossRef]

47. Yoshioka, H.; Yamazaki, M.; Harada, S. Reduction of interface states by hydrogen treatment at the aluminum oxide/4H-SiC Si-face interface. AIP Adv. 2016, 6, 105206. [CrossRef]

48. Plummer, J.D.; Deal, M.; Griffin, P.D. Silicon VLSI Technology: Fundamentals, Practice and Modelling, 1st ed.; Prentice Hall: Hoboken, NJ, USA, 2000.

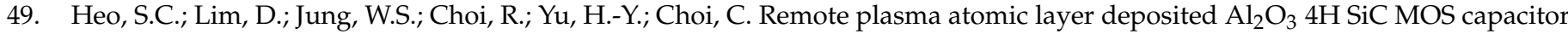
with remote $\mathrm{H}_{2}$ plasma passivation and post metallization annealing. Microelectron. Eng. 2015, 147, 239-243. [CrossRef]

50. Wang, Y.-Y.; Shen, H.-J.; Bai, Y.; Tang, Y.-D.; Liu, K.-A.; Li, C.-Z.; Liu, X.-Y. Influences of high-temperature annealing on atomic layer deposited $\mathrm{Al}_{2} \mathrm{O}_{3} / 4 \mathrm{H}-\mathrm{SiC}$. Chin. Phys. B 2013, 22, 78102. [CrossRef] 
51. Idris, M.I.; Wright, N.G.; Horsfall, A.B. Effect of Post Oxide Annealing on the Electrical and Interface $4 \mathrm{H}-\mathrm{SiC} / \mathrm{Al}_{2} \mathrm{O}_{3} \mathrm{MOS}$ Capacitors. Mater. Sci. Forum 2018, 924, 486-489. [CrossRef]

52. Linnarsson, M.K.; Hallén, A.; Khartsev, S.; Suvanam, S.S.; Usman, M. Interface between $\mathrm{Al}_{2} \mathrm{O}_{3}$ and $4 \mathrm{H}-\mathrm{SiC}$ investigated by time-of-flight medium energy ion scattering. J. Phys. D: Appl. Phys. 2017, 50, 495111. [CrossRef]

53. Liu, X.-Y.; Wang, Y.-Y.; Peng, Z.-Y.; Li, C.-Z.; Wu, J.; Bai, Y.; Tang, Y.-D.; Liu, K.-A.; Shen, H.-J. Charge trapping behavior and its origin in $\mathrm{Al}_{2} \mathrm{O}_{3} / \mathrm{SiC}$ MIS system. Chin. Phys. B 2015, 24, 87304. [CrossRef]

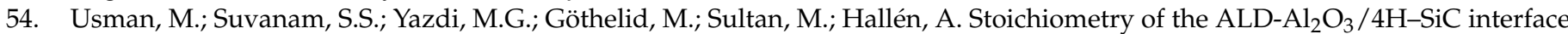
by synchrotron-based XPS. J. Phys. D Appl. Phys. 2016, 49, 255308. [CrossRef]

55. Usman, M.; Suvanam, S.S.; Linnarsson, M.; Hallén, A. Improving the quality of $\mathrm{Al}_{2} \mathrm{O}_{3} / 4 \mathrm{H}-\mathrm{SiC}$ interface for device applications Mater. Sci. Semicond. Process. 2018, 81, 118-121. [CrossRef]

56. Cheong, K.Y.; Moon, J.H.; Kim, H.J.; Bahng, W.; Kim, N.-K. Current conduction mechanisms in atomic-layer-deposited $\mathrm{HfO} 2 /$ nitrided $\mathrm{SiO}_{2}$ stacked gate on $4 \mathrm{H}$ silicon carbide. J. Appl. Phys. 2008, 103, 84113. [CrossRef]

57. Cheong, K.Y.; Moon, J.H.; Park, T.J.; Kim, J.H.; Hwang, C.S.; Kim, H.J.; Bahng, W.; Kim, N.-K. Improved Electronic Performance of $\mathrm{HfO}_{2} / \mathrm{SiO}_{2}$ Stacking Gate Dielectric on $4 \mathrm{H}$ SiC. IEEE Trans. Electron Devices 2007, 54, 3409-3413. [CrossRef]

58. Afanas'Ev, V.V.; Stesmans, A.; Chen, F.; Campbell, S.A.; Smith, R. HfO 2 -based insulating stacks on 4H-SiC(0001). Appl. Phys. Lett. 2003, 82, 922. [CrossRef]

59. Moon, J.H.; Eom, D.I.; No, S.Y.; Song, H.K.; Yim, J.H.; Na, H.J.; Lee, J.B.; Kim, H.J. Electrical Properties of the La $2 \mathrm{O}_{3} / 4 \mathrm{H}_{-} \mathrm{SiC}$ Interface Prepared by Atomic Layer Deposition Using $\mathrm{La}(\mathrm{iPrCp})_{3}$ and $\mathrm{H}_{2} \mathrm{O}$. Mater. Sci. Forum 2006, 527-529, 1083. [CrossRef]

60. Wang, Y.; Jia, R.; Zhao, Y.; Li, C.; Zhang, Y. Investigation of Leakage Current Mechanisms in $\mathrm{La}_{2} \mathrm{O}_{3} / \mathrm{SiO}_{2} / 4 \mathrm{H}-\mathrm{SiC} \mathrm{MOS}$ Capacitors with Varied $\mathrm{SiO}_{2}$ Thickness. J. Electron. Mater. 2016, 45, 5600-5605. [CrossRef]

61. Zhao, P.; Rusli; Lok, B.; Lai, F.; Tin, C.; Zhao, J.; Yar, R. Investigation of $\mathrm{Ta}_{2} \mathrm{O}_{5} / \mathrm{SiO}_{2} / 4 \mathrm{H}-\mathrm{SiC}$ MIS capacitors. Microelectron. Eng. 2005, 83, 58-60. [CrossRef]

62. Wolborski, M.; Bakowski, M.; Pore, V.; Ritala, M.; Leskelä, M.; Schöner, A.; Hallén, A. Characterization of Aluminium and Titanium Oxides Deposited on 4H-SiC by Atomic Layer Deposition Technique. Mater. Sci. Forum 2005, 483-485, 701-704. [CrossRef]

63. Nigro, R.L.; Schilirò, E.; Fiorenza, P.; Roccaforte, F. Nanolaminated $\mathrm{Al}_{2} \mathrm{O}_{3} / \mathrm{HfO}_{2}$ dielectrics for silicon carbide based devices. J. Vac. Sci. Technol. A 2020, 38, 32410. [CrossRef]

64. Usman, M.; Henkel, C.; Hallén, A. $\mathrm{HfO}_{2} / \mathrm{Al}_{2} \mathrm{O}_{3}$ Bilayered High-kDielectric for Passivation and Gate Insulator in $4 \mathrm{H}-\mathrm{SiC}$ Devices ECS J. Solid State Sci. Technol. 2013, 2, N3087-N3091. [CrossRef]

65. Zhao, F.; Amnuayphol, O.; Cheong, K.Y.; Wong, Y.H.; Jiang, J.-Y.; Huang, C.-F. Post deposition annealing effect on properties of $\mathrm{Y}_{2} \mathrm{O}_{3} / \mathrm{Al}_{2} \mathrm{O}_{3}$ stacking gate dielectric on $4 \mathrm{H}-\mathrm{SiC}$. Mater. Lett. 2019, 245, 174-177. [CrossRef]

66. Król, K.; Sochacki, M.; Taube, A.; Kwietniewski, N.; Gierałtowska, S.; Wachnicki, Ł.; Godlewski, M.; Szmidt, J. Influence of Atomic Layer Deposition Temperature on the Electrical Properties of $\mathrm{Al} / \mathrm{ZrO}_{2} / \mathrm{SiO}_{2} / 4 \mathrm{H}-\mathrm{SiC}$ Metal-Oxide Semiconductor Structures. Phys. Status Solidi 2018, 215, 1700882. [CrossRef]

67. Kerr, A.J.; Chagarov, E.; Gu, S.; Kaufman-Osborn, T.; Madisetti, S.; Wu, J.; Asbeck, P.M.; Oktyabrsky, S.; Kummel, A.C. Preparation of gallium nitride surfaces for atomic layer deposition of aluminum oxide. J. Chem. Phys. 2014, 141, 104702. [CrossRef] [PubMed]

68. Eller, B.S.; Yang, J.; Nemanich, R.J. Electronic surface and dielectric interface states on GaN and AlGaN. J. Vac. Sci. Technol. A Vac. Surf. Film. 2013, 31, 50807. [CrossRef]

69. Nepal, N.; Garces, N.Y.; Meyer, D.J.; Hite, J.; Mastro, M.A.; Eddy, J.C.R. Assessment of GaN Surface Pretreatment for Atomic Layer Deposited High-kDielectrics. Appl. Phys. Express 2011, 4, 55802. [CrossRef]

70. Duan, T.L.; Pan, J.S.; Ang, D.S. Interfacial chemistry and valence band offset between $\mathrm{GaN}_{\text {and }} \mathrm{Al}_{2} \mathrm{O}_{3}$ studied by X-ray photoelectron spectroscopy. Appl. Phys. Lett. 2013, 102, 201604. [CrossRef]

71. Brennan, B.; Qin, X.; Dong, H.; Kim, J.; Wallace, R.M. In Situ atomic layer deposition half cycle study of $\mathrm{Al}_{2} \mathrm{O}_{3}$ growth on $\mathrm{AlGaN}$ Appl. Phys. Lett. 2012, 101, 211604. [CrossRef]

72. Schilirò, E.; Fiorenza, P.; Greco, G.; Roccaforte, F.; Nigro, R.L. Plasma enhanced atomic layer deposition of $\mathrm{Al}_{2} \mathrm{O}_{3}$ gate dielectric thin films on AlGaN/GaN substrates: The role of surface predeposition treatments. J. Vac. Sci. Technol. A 2017, 35, 1B140. [CrossRef]

73. Qin, X.; Dong, H.; Brennan, B.; Azacatl, A.; Kim, J.; Wallace, R.M. Impact of $\mathrm{N}_{2}$ and forming gas plasma exposure on the growth and interfacial characteristics of $\mathrm{Al}_{2} \mathrm{O}_{3}$ on AlGaN. Appl. Phys. Lett. 2013, 103, 221604. [CrossRef]

74. Long, R.D.; McIntyre, P.C. Surface Preparation and Deposited Gate Oxides for Gallium Nitride Based Metal Oxide Semiconductor Devices. Materials 2012, 5, 1297-1335. [CrossRef]

75. Qin, X.; Dong, H.; Kim, J.; Wallace, R. A crystalline oxide passivation for $\mathrm{Al}_{2} \mathrm{O}_{3} / \mathrm{AlGaN} / \mathrm{GaN}$. Appl. Phys. Lett. 2014, 105, 141604 [CrossRef]

76. Qin, X.; Wallace, R.M. In situ plasma enhanced atomic layer deposition half cycle study of $\mathrm{Al}_{2} \mathrm{O}_{3}$ on $\mathrm{AlGaN} / \mathrm{GaN}$ high electron mobility transistors. Appl. Phys. Lett. 2015, 107, 81608. [CrossRef]

77. Benrabah, S.; Legallais, M.; Besson, P.; Ruel, S.; Vauche, L.; Pelissier, B.; Thieuleux, C.; Salem, B.; Charles, M. H ${ }_{3} \mathrm{PO}_{4}$-based wet chemical etching for recovery of dry-etched GaN surfaces. Appl. Surf. Sci. 2021, 28, 152309. [CrossRef] 
78. Vauche, L.; Chanuel, A.; Martinez, E.; Roure, M.-C.; Le Royer, C.; Bécu, S.; Gwoziecki, R.; Plissonnier, M. Study of an $\mathrm{Al}_{2} \mathrm{O}_{3} / \mathrm{GaN}$ Interface for Normally Off MOS-Channel High-Electron-Mobility Transistors Using XPS Characterization: The Impact of Wet Surface Treatment on Threshold Voltage VTH. ACS Appl. Electron. Mater. 2021, 3, 1170-1177. [CrossRef]

79. Schilirò, E.; Fiorenza, P.; Greco, G.; Monforte, F.; Condorelli, G.G.; Roccaforte, F.; Giannazzo, F.; Nigro, R.L. Early Growth Stages of Aluminum Oxide $\left(\mathrm{Al}_{2} \mathrm{O}_{3}\right)$ Insulating Layers by Thermal- and Plasma-Enhanced Atomic Layer Deposition on AlGaN/GaN Heterostructures. ACS Appl. Electron. Mater. 2021, in press. [CrossRef]

80. Tanner, C.M.; Toney, M.F.; Lu, J.; Blom, H.-O.; Sawkar-Mathur, M.; Tafesse, M.A.; Chang, J.P. Engineering epitaxial $\gamma-\mathrm{Al}_{2} \mathrm{O}_{3}$ gate dielectric films on 4H-SiC. J. Appl. Phys. 2007, 102, 104112. [CrossRef]

81. Nigro, R.L.; Fiorenza, P.; Catalano, M.R.; Fisichella, G.; Roccaforte, F.; Malandrino, G. Binary and complex oxide thin films for microelectronic applications: An insight into their growth and advanced nanoscopic investigation. Surf. Coat. Technol. 2013, 230, 152-162. [CrossRef]

82. Sarkar, R.; Bhunia, S.; Nag, D.; Barik, B.C.; Das Gupta, K.; Saha, D.; Ganguly, S.; Laha, A.; Lemettinen, J.; Kauppinen, C.; et al Epi-Gd ${ }_{2} \mathrm{O}_{3} / \mathrm{AlGaN} / \mathrm{GaN}$ MOS HEMT on $150 \mathrm{~mm}$ Si wafer: A fully epitaxial system for high power application. Appl. Phys. Lett. 2019, 115, 63502. [CrossRef]

83. Jur, J.S.; Wheeler, V.D.; Lichtenwalner, D.J.; Maria, J.-P.; Johnson, M.A.L. Epitaxial growth of lanthanide oxides $\mathrm{La}_{2} \mathrm{O}_{3}$ and $\mathrm{Sc}_{2} \mathrm{O}_{3}$ on GaN. Appl. Phys. Lett. 2011, 98, 42902. [CrossRef]

84. Herrero, A.M.; Gila, B.P.; Abernathy, C.R.; Pearton, S.; Craciun, V.; Siebein, K.; Ren, F. Epitaxial growth of $\mathrm{Sc}_{2} \mathrm{O}_{3}$ films on GaN. Appl. Phys. Lett. 2006, 89, 92117. [CrossRef]

85. Nigro, R.L.; Greco, G.; Swanson, L.; Fisichella, G.; Fiorenza, P.; Giannazzo, F.; Di Franco, S.; Bongiorno, C.; Marino, A.; Malandrino, G.; et al. Potentialities of Nickel Oxide as Dielectric for GaN and SiC Devices. Mater. Sci. Forum 2013, 740-742, 777-780. [CrossRef]

86. Oh, C.S.; Youn, C.J.; Yang, G.M.; Lim, K.Y.; Yang, J.W. AlGaN/GaNAlGaN/GaN metal-oxide-semiconductor heterostructure field-effect transistor with oxidized Ni as a gate insulator. Appl. Phys. Lett. 2004, 85, 4214-4216. [CrossRef]

87. Courtade, L.; Turquat, C.; Muller, C.; Lisoni, J.; Goux, L.; Wouters, D.; Goguenheim, D.; Roussel, P.; Ortega, L. Oxidation kinetics of Ni metallic films: Formation of NiO-based resistive switching structures. Thin Solid Film. 2008, 516, 4083-4092. [CrossRef]

88. Graham, M.J.; Hussey, R.J.; Cohen, M. Influence of Oxide Structure on the Oxidation Rate of Nickel Single Crystals. J. Electrochem. Soc. 1973, 120, 1523-1529. [CrossRef]

89. Baliga, B.J. Silicon Carbide Power Devices; World Scientific Co. Pte. Ltd.: Singapore, 2005.

90. Suri, R.; Kirkpatrick, C.J.; Lichtenwalner, D.J.; Misra, V. Energy-band alignment of $\mathrm{Al}_{2} \mathrm{O}_{3}$ and HfAlO gate dielectrics deposited by atomic layer deposition on 4H-SiC. Appl. Phys. Lett. 2010, 96, 42903. [CrossRef]

91. Wright, N.G.; Poolamai, N.; Vassilevski, K.; Horsfall, A.B.; Johnson, C.M. Benefits of High-k Dielectrics in 4H-SiC Trench MOSFETs. Mater. Sci. Forum 2004, 457-460, 1433-1436. [CrossRef]

92. Ambacher, O.; Smart, J.A.; Shealy, J.R.; Weimann, N.; Chu, K.; Murphy, M.J.; Schaff, W.J.; Eastman, L.F.; Dimitrov, R.; Wittmer, L.L.; et al. Two-dimensional electron gases induced by spontaneous and piezoelectric polarization charges in N- and Ga-face AlGaN/GaN heterostructures. J. Appl. Phys. 1999, 85, 3222-3233. [CrossRef]

93. Ibbetson, J.P.; Fini, P.T.; Ness, K.D.; DenBaars, S.P.; Speck, J.S.; Mishra, U.K. Polarization effects, surface states, and the source of electrons in AlGaN/GaN heterostructure field effect transistors. Appl. Phys. Lett. 2000, 77, 250-252. [CrossRef]

94. Mishra, U.K.; Likun, S.; Kazior, T.E.; Wu, Y.-F. GaN-Based RF Power Devices and Amplifiers. Proc. IEEE 2008, 96, 287-305. [CrossRef]

95. Ishida, M.; Uemoto, Y.; Ueda, T.; Tanaka, T.; Ueda, D. GaN power switching devices. In Proceedings of the 2010 International Power Electronics Conference-ECCE ASIA, Sapporo, Japan, 21-24 June 2010; pp. 1014-1017. [CrossRef]

96. Kikkawa, T.; Makiyama, K.; Ohki, T.; Kanamura, M.; Imanishi, K.; Hara, N.; Joshin, K. High performance and high reliability AlGaN/GaN HEMTs. Phys. Status Solidi 2009, 206, 1135-1144. [CrossRef]

97. Chang, Y.C.; Chang, W.H.; Chiu, H.C.; Tung, L.T.; Lee, C.H.; Shiu, K.H.; Hong, M.; Kwo, J.; Hong, J.M.; Tsai, C.C. Inversionchannel GaN metal-oxide-semiconductor field-effect transistor with atomic-layer-deposited $\mathrm{Al}_{2} \mathrm{O}_{3}$ as gate dielectric. Appl. Phys. Lett. 2008, 93, 53504. [CrossRef]

98. Hashizume, T.; Ootomo, S.; Hasegawa, H. Suppression of current collapse in insulated gate AlGaN/GaN heterostructure field-effect transistors using ultrathin $\mathrm{Al}_{2} \mathrm{O}_{3}$ dielectric. Appl. Phys. Lett. 2003, 83, 2952-2954. [CrossRef]

99. Chen, K.J.; Zhou, C. Enhancement-mode AlGaN/GaN HEMT and MIS-HEMT technology. Phys. Status Solidi A 2011, 208,434 [CrossRef]

100. Roccaforte, F.; Fiorenza, P.; Greco, G.; Nigro, R.L.; Giannazzo, F.; Patti, A.; Saggio, M. Challenges for energy efficient wide band gap semiconductor power devices. Phys. Status Solidi 2014, 211, 2063-2071. [CrossRef]

101. Tanner, C.M.; Choi, J.; Chang, J.P. Electronic structure and band alignment at the $\mathrm{HfO}_{2} / 4 \mathrm{H}-\mathrm{SiC}$ interface. J. Appl. Phys. 2007, 101, 34108. [CrossRef]

102. Mahapatra, R.; Chakraborty, A.K.; Horsfall, A.B.; Wright, N.; Beamson, G.; Coleman, K. Energy-band alignment of $\mathrm{HfO}_{2} / \mathrm{SiO}_{2} / \mathrm{SiC}$ gate dielectric stack. Appl. Phys. Lett. 2008, 92, 42904. [CrossRef]

103. Wang, Y.; Jia, R.; Li, C.; Zhang, Y. Electric properties of $\mathrm{La}_{2} \mathrm{O}_{3} / \mathrm{SiO}_{2} / 4 \mathrm{H}-\mathrm{SiC} \mathrm{MOS}$ capacitors with different annealing temperatures. AIP Adv. 2015, 5, 87166. [CrossRef]

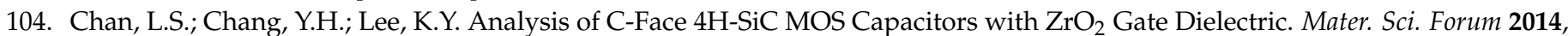
778-780, 635-638. [CrossRef] 
105. Kwietniewski, N.; Masłyk, M.; Werbowy, A.; Taube, A.; Gierałtowska, S.; Wachnicki, Ł.; Sochacki, M. Electrical characterization of $\mathrm{ZnO} / 4 \mathrm{H}-\mathrm{SiC}$ n-p heterojunction diode. Phys. Status Solidi 2016, 213, 1120-1124. [CrossRef]

106. Siddiqui, A.; Khosa, R.Y.; Usman, M. High-k dielectrics for $4 \mathrm{H}$-silicon carbide: Present status and future perspectives. J. Mater. Chem. C 2021, 9, 5055-5081. [CrossRef]

107. Hino, S.; Hatayama, T.; Kato, J.; Tokumitsu, E.; Miura, N.; Oomori, T. High channel mobility 4H-SiC metal-oxide-semiconductor field-effect transistor with low temperature metal-organic chemical-vapor deposition grown $\mathrm{Al}_{2} \mathrm{O}_{3}$ gate insulator. Appl. Phys. Lett. 2008, 92, 183503. [CrossRef]

108. Hatayama, T.; Hino, S.; Miura, N.; Oomori, T.; Tokumitsu, E. Remarkable Increase in the Channel Mobility of SiC-MOSFETs by Controlling the Interfacial $\mathrm{SiO}_{2}$ Layer Between $\mathrm{Al}_{2} \mathrm{O}_{3}$ and $\mathrm{SiC}$. IEEE Trans. Electron Devices 2008, 55, 2041-2045. [CrossRef]

109. Fiorenza, P.; Greco, G.; Iucolano, F.; Patti, A.; Roccaforte, F. Channel Mobility in GaN Hybrid MOS-HEMT Using SiO 2 as Gate Insulator. IEEE Trans. Electron Devices 2017, 64, 2893-2899. [CrossRef]

110. Frazzetto, A.; Giannazzo, F.; Fiorenza, P.; Raineri, V.; Roccaforte, F. Limiting mechanism of inversion channel mobility in Al-implanted lateral 4H-SiC metal-oxide semiconductor field-effect transistors. Appl. Phys. Lett. 2011, 99, 72117. [CrossRef]

111. Arith, F.; Urresti, J.; Vasilevskiy, K.; Olsen, S.; Wright, N.; O'Neill, A. Increased Mobility in Enhancement Mode 4H-SiC MOSFET Using a Thin $\mathrm{SiO}_{2} / \mathrm{Al}_{2} \mathrm{O}_{3}$ Gate Stack. IEEE Electron Device Lett. 2018, 39, 564-567. [CrossRef]

112. Yang, X.; Lee, B.; Misra, V. Electrical Characteristics of $\mathrm{SiO}_{2}$ Deposited by Atomic Layer Deposition on $4 \mathrm{H}-\mathrm{SiC}$ After Nitrous Oxide Anneal. IEEE Trans. Electron Devices 2016, 63, 2826-2830. [CrossRef]

113. Yang, X.; Lee, B.; Misra, V. High Mobility 4H-SiC Lateral MOSFETs Using Lanthanum Silicate and Atomic Layer Deposited SiO 2 . IEEE Electron Device Lett. 2015, 36, 312-314. [CrossRef]

114. Watanabe, H.; Kirino, T.; Uenishi, Y.; Chanthaphan, A.; Yoshigoe, A.; Teraoka, Y.; Mitani, S.; Nakano, Y.; Nakamura, T.; Hosoi, T.; et al. Impact of Stacked $\mathrm{AlON} / \mathrm{SiO}_{2}$ Gate Dielectrics for SiC Power Devices. ECS Trans. 2011, 35, 265-274. [CrossRef]

115. Hosoi, T.; Kagei, Y.; Kirino, T.; Watanabe, Y.; Kozono, K.; Mitani, S.; Nakano, Y.; Nakamura, T.; Watanabe, H. Improved Characteristics of 4H-SiC MISFET with AlON/Nitrided $\mathrm{SiO}_{2}$ Stacked Gate Dielectrics. Mater. Sci. Forum 2010, 645-648, 991-994. [CrossRef]

116. Chanthaphan, A.; Hosoi, T.; Nakano, Y.; Nakamura, T.; Shimura, T.; Watanabe, H. Improved bias-temperature instability characteristics in SiC metal-oxide-semiconductor devices with aluminum oxynitride dielectrics. Appl. Phys. Lett. 2014, 104, 122105. [CrossRef]

117. Jayawardhena, I.U.; Ramamurthy, R.P.; Morisette, D.; Ahyi, A.C.; Thorpe, R.; Kuroda, M.A.; Feldman, L.C.; Dhar, S. Effect of surface treatments on $\mathrm{ALD} \mathrm{Al}{ }_{2} \mathrm{O}_{3} / 4 \mathrm{H}-\mathrm{SiC}$ metal-oxide-semiconductor field-effect transistors. J. Appl. Phys. 2021, 129 , 75702. [CrossRef]

118. Saadat, O.I.; Chung, J.W.; Piner, E.L.; Palacios, T. Gate-First AlGaN/GaN HEMT Technology for High-Frequency Applications. IEEE Electron Device Lett. 2009, 30, 1254-1256. [CrossRef]

119. Zhang, Y.; Sun, M.; Joglekar, S.J.; Fujishima, T.; Palacios, T. Threshold voltage control by gate oxide thickness in fluorinated GaN metal-oxide-semiconductor high-electron-mobility transistors. Appl. Phys. Lett. 2013, 103, 33524. [CrossRef]

120. Hou, B.; Ma, X.; Zhu, J.; Yang, L.; Chen, W.; Mi, M.; Zhu, Q.; Chen, L.; Zhang, R.; Zhang, M.; et al. 0.9-A/mm, 2.6-V Flash-Like Normally-Off $\mathrm{Al}_{2} \mathrm{O}_{3} / \mathrm{AlGaN} / \mathrm{GaN}$ MIS-HEMTs Using Charge Trapping Technique. IEEE Electron Device Lett. 2018, 39, 397-400. [CrossRef]

121. Schilirò, E.; Fiorenza, P.; Bongiorno, C.; Spinella, C.; Di Franco, S.; Greco, G.; Nigro, R.L.; Roccaforte, F. Correlating electron trapping and structural defects in $\mathrm{Al}_{2} \mathrm{O}_{3}$ thin films deposited by plasma enhanced atomic layer deposition. AIP Adv. 2020, 10, 125017. [CrossRef]

122. Kubo, T.; Egawa, T. Electrical characteristics and interface properties of ALD-HfO 2 / AlGaN/GaN MIS-HEMTs fabricated with post-deposition annealing. Semicond. Sci. Technol. 2017, 32, 125016. [CrossRef]

123. Huang, Z.; Liu, J.; Huang, X.; Yao, J.; Zhang, J.; Guo, Y. Analysis of Interface Properties in AlGaN/GaN MIS-HEMTs with HfO 2 and SiNx Gate Dielectric. In Proceedings of the 2020 10th International Conference on Power and Energy Systems (ICPES), Chengdu, China, 25-27 December 2020; pp. 549-552.

124. Liu, C.; Chor, E.F.; Tan, L.S. Investigations of $\mathrm{HfO}_{2} / \mathrm{AlGaN} / \mathrm{GaN}$ metal-oxide-semiconductor high electron mobility transistors. Appl. Phys. Lett. 2006, 88, 173504. [CrossRef]

125. Lin, Y.C.; Lin, T.W.; Wu, C.H.; Yao, J.N.; Hsu, H.T.; Shih, W.C.; Kakushima, K.; Tsutsui, K.; Iwai, H.; Chang, E.Y. Optimization of gate insulator material for GaN MIS-HEMT. In Proceedings of the 2016 28th International Symposium on Power Semiconductor Devices and ICs (ISPSD), Prague, Czech Republic, 12-16 June 2016; pp. 115-118. [CrossRef]

126. Shi, Y.-T.; Xu, W.-Z.; Zeng, C.-K.; Ren, F.-F.; Ye, J.-D.; Zhou, D.; Chen, D.-J.; Zhang, R.; Zheng, Y.; Lu, H. High-k HfO 2 -Based $\mathrm{AlGaN} / \mathrm{GaN}$ MIS-HEMTs With $\mathrm{Y}_{2} \mathrm{O}_{3}$ Interfacial Layer for High Gate Controllability and Interface Quality. IEEE J. Electron Devices Soc. 2020, 8, 15-19. [CrossRef]

127. Cui, X.; Cheng, W.; Hua, Q.; Liang, R.; Hu, W.; Wang, Z.L. Enhanced performances of AlGaN/GaN HEMTs with dielectric engineering of HfZrOx. Nano Energy 2020, 68, 104361. [CrossRef]

128. Kumar, S.; Kumar, H.; Vura, S.; Pratiyush, A.S.; Charan, V.S.; Dolmanan, S.B.; Tripathy, S.; Muralidharan, R.; Nath, D.N. Investigation of $\mathrm{Ta}_{2} \mathrm{O}_{5}$ as an Alternative High-k Dielectric for InAlN/GaN MOS-HEMT on Si. IEEE Trans. Electron Devices 2019, 66, 1230-1235. [CrossRef] 
129. Balachander, K.; Arulkumaran, S.; Ishikawa, H.; Baskar, K.; Egawa, T. Studies on electron beam evaporated $\mathrm{ZrO} 2 / \mathrm{AlGaN} / \mathrm{GaN}$ metal-oxide-semiconductor high-electron-mobility transistors. Phys. Status Solidi 2005, 202, R16-R18. [CrossRef]

130. Kuzmik, J.; Pozzovivo, G.; Abermann, S.; Gonschorek, M.; Feltin, E.; Grandjean, N.; Bertagnolli, E.; Pogany, D.; Carlin, J.-F.; Strasser, G. Technology and Performance of InAlN/AlN/GaN HEMTs With Gate Insulation and Current Collapse Suppression Using $\mathrm{ZrO}_{2}$ or $\mathrm{HfO}_{2}$. IEEE Trans. Electron Devices 2008, 55, 937-941. [CrossRef]

131. Ye, G.; Wang, H.; Arulkumaran, S.; Ng, G.I.; Hofstetter, R.; Li, Y.; Anand, M.J.; Ang, K.S.; Maung, Y.K.T.; Foo, S.C. Atomic layer deposition of $\mathrm{ZrO}_{2}$ as gate dielectrics for $\mathrm{AlGaN} / \mathrm{GaN}$ metal-insulator-semiconductor high electron mobility transistors on silicon. Appl. Phys. Lett. 2013, 103, 142109. [CrossRef]

132. Gao, Z.; Romero, M.F.; Redondo-Cubero, A.; Pampillon, M.A.; Andres, E.S.; Calle, F. Effects of $\mathrm{Gd}_{2} \mathrm{O}_{3} \mathrm{Gate}^{\mathrm{Dielectric}}$ on Proton-Irradiated AlGaN/GaN HEMTs. IEEE Electron Device Lett. 2017, 38, 611-614. [CrossRef]

133. Fiorenza, P.; Schilirò, E.; Greco, G.; Vivona, M.; Cannas, M.; Giannazzo, F.; Nigro, R.L.; Roccaforte, F. Temperature and time dependent electron trapping in $\mathrm{Al}_{2} \mathrm{O}_{3}$ thin films onto AlGaN/GaN heterostructures. Appl. Surf. Sci. 2021, 579, 152136. [CrossRef]

134. Li, Z.; Chow, T.P. Channel scaling of hybrid GaN MOS-HEMTs. Solid-State Electron. 2011, 56, 111-115. [CrossRef]

135. Roccaforte, F.; Greco, G.; Fiorenza, P.; Iucolano, F. An Overview of Normally-Off GaN-Based High Electron Mobility Transistors. Materials 2019, 12, 1599. [CrossRef] [PubMed]

136. Fiorenza, P.; Greco, G.; Iucolano, F.; Patti, A.; Roccaforte, F. Slow and fast traps in metal-oxide-semiconductor capacitors fabricated on recessed AlGaN/GaN heterostructures. Appl. Phys. Lett. 2015, 106, 142903. [CrossRef]

137. Hosoi, T.; Watanabe, K.; Nozaki, M.; Yamada, T.; Shimura, T.; Watanabe, H. Mobility enhancement in recessed-gate AlGaN/GaN MOS-HFETs using an AlON gate insulator. Jpn. J. Appl. Phys. 2019, 58, SCCD16. [CrossRef]

138. Oka, T.; Nozawa, T. AlGaN/GaN Recessed MIS-Gate HFET With High-Threshold-Voltage Normally-Off Operation for Power Electronics Applications. IEEE Electron Device Lett. 2008, 29, 668-670. [CrossRef]

139. Greco, G.; Fiorenza, P.; Iucolano, F.; Severino, A.; Giannazzo, F.; Roccaforte, F. Conduction Mechanisms at Interface of AlN/SiN Dielectric Stacks with AlGaN/GaN Heterostructures for Normally-off High Electron Mobility Transistors: Correlating Device Behavior with Nanoscale Interfaces Properties. ACS Appl. Mater. Interfaces 2017, 9, 35383-35390. [CrossRef]

140. Asahara, R.; Nozaki, M.; Yamada, T.; Ito, J.; Nakazawa, S.; Ishida, M.; Ueda, T.; Yoshigoe, A.; Hosoi, T.; Shimura, T.; et al. Effect of nitrogen incorporation into Al-based gate insulators in AlON/AlGaN/GaN metal-oxide-semiconductor structures. Appl. Phys. Express 2016, 9, 101002. [CrossRef]

141. Im, K.-S.; Ha, J.-B.; Kim, K.-W.; Lee, J.-S.; Kim, D.-S.; Hahm, S.-H.; Lee, J.-H. Normally off GaN MOSFET Based on AlGaN/GaN Heterostructure with Extremely High 2DEG Density Grown on Silicon Substrate. IEEE Electron Device Lett. 2010, 31, 192-194. [CrossRef]

142. Kim, K.-W.; Jung, S.-D.; Kim, D.-S.; Kang, H.-S.; Im, K.-S.; Oh, J.-J.; Ha, J.-B.; Shin, J.-K.; Lee, J.-H. Effects of TMAH Treatment on Device Performance of Normally off $\mathrm{Al}_{2} \mathrm{O}_{3} / \mathrm{GaN}$ MOSFET. IEEE Electron Device Lett. 2011, 32, 1376-1378. [CrossRef]

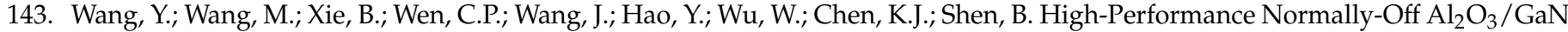
MOSFET Using a Wet Etching-Based Gate Recess Technique. IEEE Electron Device Lett. 2013, 34, 1370-1372. [CrossRef]

144. Wang, M.; Wang, Y.; Zhang, C.; Xie, B.; Wen, C.P.; Wang, J.; Hao, Y.; Wu, W.; Chen, K.J.; Shen, B. 900 V/1.6 m $\Omega \cdot \mathrm{cm}^{2}$ Normally Off $\mathrm{Al}_{2} \mathrm{O}_{3} / \mathrm{GaN}$ MOSFET on Silicon Substrate. IEEE Trans. Electron Devices 2014, 61, 2035-2040. [CrossRef]

145. Yao, Y.; He, Z.; Yang, F.; Shen, Z.; Zhang, J.; Ni, Y.; Li, J.; Wang, S.; Zhou, G.; Zhong, J.; et al. Normally-off GaN recessed-gate MOSFET fabricated by selective area growth technique. Appl. Phys. Express 2013, 7, 16502. [CrossRef]

146. He, L.; Yang, F.; Li, L.; Chen, Z.; Shen, Z.; Zheng, Y.; Yao, Y.; Ni, Y.; Zhou, D.; Zhang, X.; et al. High Threshold Voltage Uniformity and Low Hysteresis Recessed-Gate $\mathrm{Al}_{2} \mathrm{O}_{3} / \mathrm{AIN} / \mathrm{GaN}$ MISFET by Selective Area Growth. IEEE Trans. Electron Devices 2017, 64, 1554-1560. [CrossRef]

147. Tao, M.; Liu, S.; Xie, B.; Wen, C.P.; Wang, J.; Hao, Y.; Wu, W.; Cheng, K.; Shen, B.; Wang, M. Characterization of 880 V Normally Off GaN MOSHEMT on Silicon Substrate Fabricated With a Plasma-Free, Self-Terminated Gate Recess Process. IEEE Trans. Electron Devices 2018, 65, 1453-1457. [CrossRef]

148. Ťapajna, M.; Válik, L.; Gucmann, F.; Gregusova, D.; Fröhlich, K.; Haščík, Š.; Dobročka, E.; Tóth, L.; Pécz, B.; Kuzmík, J. Lowtemperature atomic layer deposition-grown $\mathrm{Al}_{2} \mathrm{O}_{3}$ gate dielectric for GaN/AlGaN/GaN MOS HEMTs: Impact of deposition conditions on interface state density. J. Vac. Sci. Technol. B 2017, 35, 1A107. [CrossRef]

149. Fiorenza, P.; Greco, G.; Schilirò, E.; Iucolano, F.; Nigro, R.L.; Roccaforte, F. Determining oxide trapped charges in $\mathrm{Al}_{2} \mathrm{O}_{3}$ insulating films on recessed $\mathrm{AlGaN} / \mathrm{GaN}$ heterostructures by gate capacitance transients measurements. Jpn. J. Appl. Phys. 2018, 57, 050307. [CrossRef]

150. Zhao, Y.; Wang, C.; Zheng, X.; Ma, X.; He, Y.; Liu, K.; Li, A.; Peng, Y.; Zhang, C.; Hao, Y. Effects of recess depths on performance of $\mathrm{AlGaN} / \mathrm{GaN}$ power MIS-HEMTs on the Si substrates and threshold voltage model of different recess depths for the using $\mathrm{HfO}_{2}$ gate insulator. Solid-State Electron. 2020, 163, 107649. [CrossRef]

151. Anderson, T.J.; Wheeler, V.D.; Shahin, D.I.; Tadjer, M.J.; Koehler, A.D.; Hobart, K.D.; Christou, A.; Kub, F.J.; Eddy, C.R. Enhancement mode $\mathrm{AlGaN} / \mathrm{GaN}$ MOS high-electron-mobility transistors with $\mathrm{ZrO}_{2}$ gate dielectric deposited by atomic layer deposition. Appl. Phys. Express 2016, 9, 11-14. [CrossRef]

152. Jiang, H.; Tang, C.W.; Lau, K.M. Enhancement-Mode GaN MOS-HEMTs With Recess-Free Barrier Engineering and High- $k$ ZrO 2 Gate Dielectric. IEEE Electron Device Lett. 2018, 39, 405-408. [CrossRef] 
153. Cai, Y.; Zhang, Y.; Liang, Y.; Mitrovic, I.Z.; Wen, H.; Liu, W.; Zhao, C. Low on -State Resistance Normally- off AlGaN/GaN MIS-HEMTs with Partially Recessed Gate and ZrOx. IEEE Trans. Electron Devices 2021, 68, 4310-4316. [CrossRef]

154. Hu, Q.; Li, S.; Li, T.; Wang, X.; Li, X.; Wu, Y. Channel Engineering of Normally-OFF AlGaN/GaN MOS-HEMTs by Atomic Layer Etching and High- $\kappa$ Dielectric. IEEE Electron Device Lett. 2018, 39, 1377-1380. [CrossRef]

155. Lin, Y.C.; Huang, Y.X.; Huang, G.N.; Wu, C.H.; Yao, J.N.; Chu, C.M.; Chang, S.; Hsu, C.C.; Lee, J.H.; Kakushima, K.; et al. Enhancement-Mode GaN MIS-HEMTs With LaHfOx Gate Insulator for Power Application. IEEE Electron Device Lett. 2017, 38, 1101-1104. [CrossRef]

156. Greco, G.; Iucolano, F.; Roccaforte, F. Review of technology for normally-off HEMTs with p-GaN gate. Mater. Sci. Semicond. Process. 2018, 78, 96-106. [CrossRef]

157. Li, Y.; Guo, Y.; Zhang, K.; Zou, X.; Wang, J.; Kong, Y.; Chen, T.; Jiang, C.; Fang, G.; Liu, C.; et al. Positive Shift in Threshold Voltage Induced by $\mathrm{CuO}$ and $\mathrm{NiOx}$ Gate in AlGaN/GaN HEMTs. IEEE Trans. Electron Devices 2017, 64, 3139-3144. [CrossRef]

158. Kaneko, N.; Machida, O.; Yanagihara, M.; Iwakami, S.; Baba, R.; Goto, H.; Iwabuchi, A. Normally-off AlGaN/GaN HFETs using NiOx gate with recess. In Proceedings of the 2009 21st International Symposium on Power Semiconductor Devices \& IC's, Barcelona, Spain, 14-18 June 2009; pp. 25-28. [CrossRef]

159. Wang, L.; Li, L.; Xie, T.; Wang, X.; Liu, X.; Ao, J.-P. Threshold voltage tuning in AlGaN/GaN HFETs with p-type Cu $2 \mathrm{O}$ gate synthesized by magnetron reactive sputtering. Appl. Surf. Sci. 2018, 437, 98-102. [CrossRef]

160. Kohmoto, O.; Nakagawa, H.; Isagawa, Y.; Chayahara, A. Effect of heat treatment on the oxygen content and resistivity in sputtered NiO films. J. Magn. Magn. Mater. 2001, 226-230, 1629-1630. [CrossRef]

161. Raebiger, H.; Lany, S.; Zunger, A. Origins of thep-type nature and cation deficiency in $\mathrm{Cu}_{2} \mathrm{O}$ and related materials. Phys. Rev. $B$ 2007, 76, 45209. [CrossRef] 